\title{
Rheological Properties of Defense Waste Processing Facility Melter Feeds
}

\author{
Topical Report \\ August 1, 1995 - October 30, 1996
}

Work Performed Under Contract No.: DE-FG21-95EW55094

For

U.S. Department of Energy

Office of Fossil Energy

Federal Energy Technology Center

P.O. Box 880

Morgantown, West Virginia 26507-0880

\author{
By \\ Florida International University \\ Hemispheric Center for Environmental Technology (HCET) \\ Center for Engineering \& Applied Sciences \\ 10555 West Flagler Street \\ EAS-2100 \\ Miami, Florida 33174
}




\section{Disclaimer}

This report was prepared as an account of work sponsored by an agency of the United States Government. Neither the United States Government nor any agency thereof, nor any of their employees, makes any warranty, express or implied, or assumes any legal liability or responsibility for the accuracy, completeness, or usefulness of any information, apparatus, product, or process disclosed, or represents that its use would not infringe privately owed rights. Reference herein to any specific commercial product, process, or service by trade name, trademark, manufacturer, or otherwise does not necessarily constitute or imply its endorsement, recommendation, or favoring by the United States Government or any agency thereof. The views and opinions of authors expressed herein do not necessarily state or reflect those of the United States Government or any agency thereof. 


\section{DISCLAIMER}

Portions of this document may be illegible electronic image products. Images are produced from the best available original document. 


\section{TABLE OF CONTENTS}

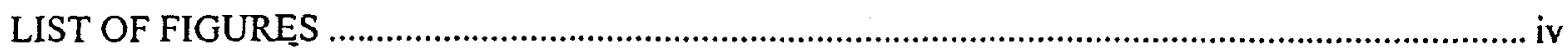

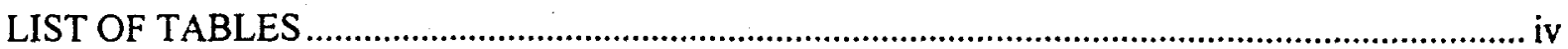

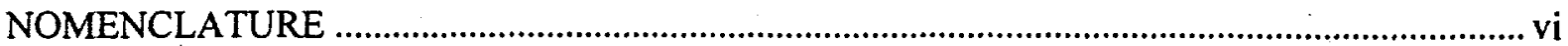

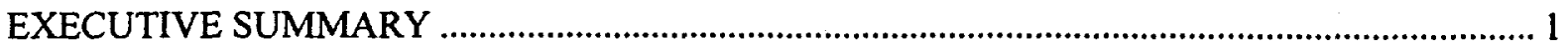

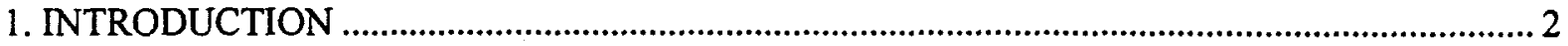

1.1 FACTORS AFFECTING THE VISCOSITY OF SLURRIES ..................................... 3

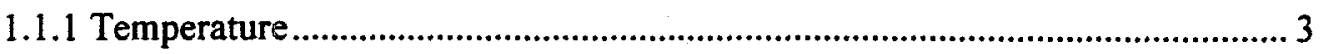

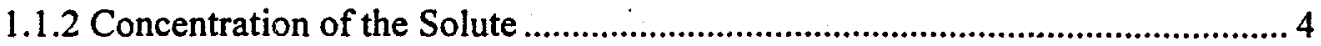

1.1.3 Molecular Weight of the Solute .................................................................. 5

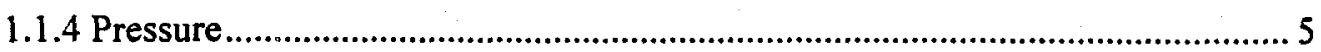

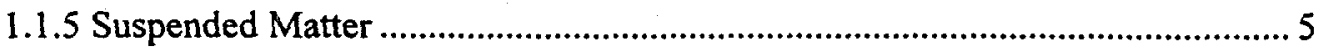

1.2 REVIEW OF PREVIOUS INVESTIGATIONS ........................................... 6

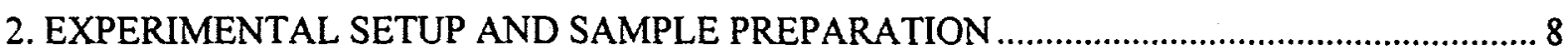

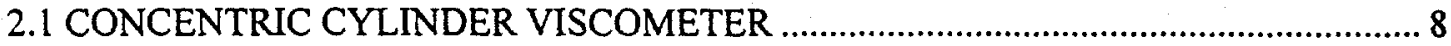

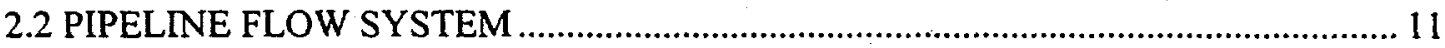

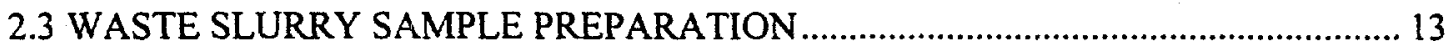

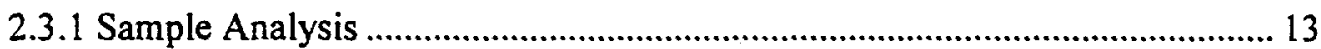

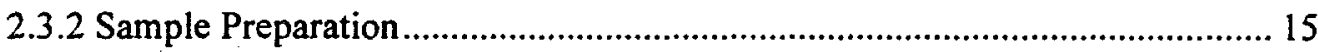

3. EXPERIMENTAL STUDY USING A ROTATIONAL VISCOMETER .................................. 17

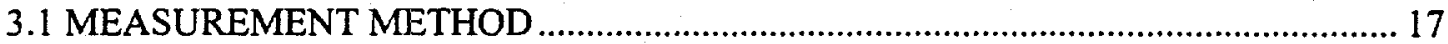

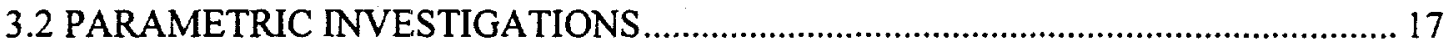

3.2.1 Effect of the Concentration of Solids ........................................................ 17

3.2.2 Effects of the $\mathrm{pH}$ on the Slurries Tested........................................................ 20

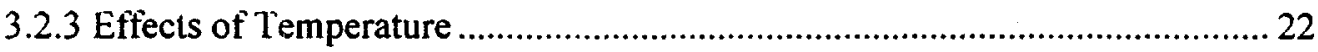

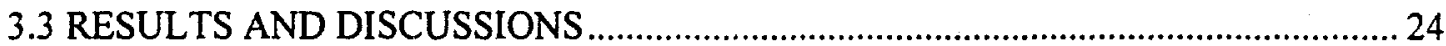

4. EXPERIMENTAL STUDY USING THE PIPELINE FLOW SYSTEM ................................ 26

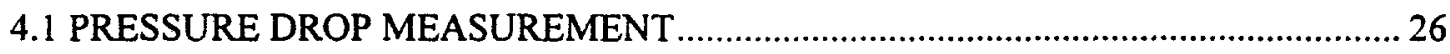

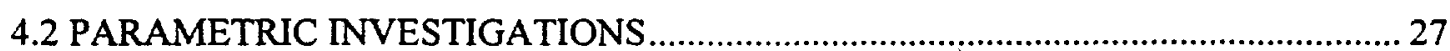

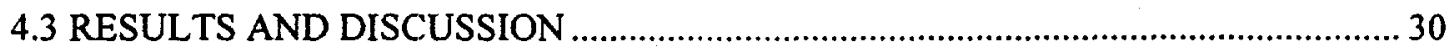

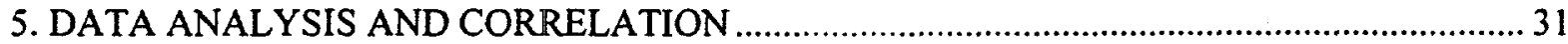

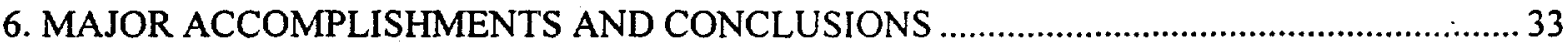

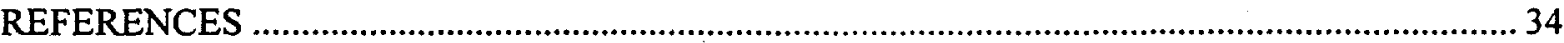




\section{LIST OF FIGURES}

Figure 1. Viscosity as a function of temperature and concentration (high viscosity standards)......4

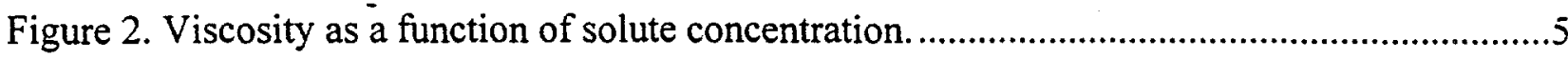

Figure 3. Rotational viscometer calibration curve using the low viscosity standard......................9

Figure 4. Schematic of the experimental pipeline flow system...............................................12

Figure 5. Relationship between the solids concentration and the suspension ratio........................15

Figure 6. Viscosity (in linear scale) as a function of solids concentration. ....................................18

Figure 7. Viscosity (in long scale) as a function of solids concentration (SRS slurry). .................18

Figure 8. Viscosity (in linear scale) as a function of solids concentration (Hanford slurry).........19

Figure 9. Viscosity (in long scale) as a function of solids concentration (Hanford slurry)...........19

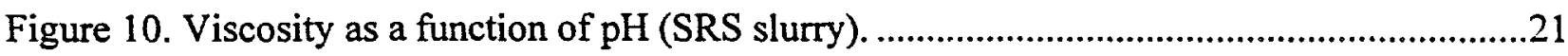

Figure 11. Viscosity as a function of $\mathrm{pH}$ (Hanford slurry. The $\mathrm{pH}$ was adjusted using sulfuric acid for the upper and bottom curves and sodium hydroxide for the middle curve).........21

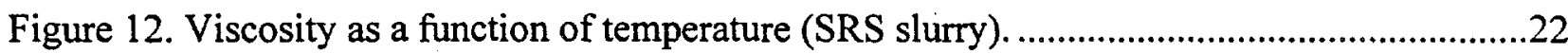

Figure 13. Viscosity as a function of temperature (SRS slurry) ....................................................23

Figure 14. Viscosity as a function of temperature (Hanford slurry) ........................................24

Figure 15. Pressure drop as a function of solids concentration (SRS slurry). ................................28

Figure 16. Pressure drop as a function of $\mathrm{pH}$ (SRS slurry)..........................................................29

Figure 17. Pressure drop as a function of temperature (SRS slurry). .............................................29 


\section{LIST OF TABLES}

Table 1. Calibration Data from (Calibration standard: 103 cf $@ 25^{\circ} \mathrm{C}$ ).......................................

Table 2. Viscosity Range of the High Viscosity Standard.......................................................10

Table 3. Calibration Data Using High Viscosity Standards: S200 ..........................................10

Table 4. Calibration Data Using High Viscosity Standards: S2000 ..........................................11

Table 5. Analytical Results of the SRS Sludge (ID\# 32897) ........................................................13

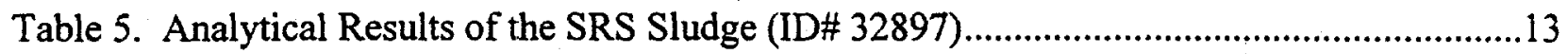

Table 6. Analytical Results of the Handford Sludge (ID\# 200053234)......................................

Table 7. Prepared Sample Concentration......................................................................................

Table 8. PH Value Adjusted with $\mathrm{H}_{2} \mathrm{SO}_{4}$ and $\mathrm{NaOH}$

Table 9. Experimental Cases in the Pipeline Flow System ……...................................................27 
A

Am

$\mathrm{A}_{0}$

B

$\mathrm{C}$

$\mathrm{C}_{\max }$

D

F

$\Delta \mathrm{P}$

L

$T$

\section{GREEK SYMBOLS}

$\mu$

\section{SUBSCRIPTS}

$\max$

0
Parameter in the viscosity model (cP)

Reading of pressure transducer (Am)

Reading of pressure transducer at zero flow rate of slurry (Am)

Parameter in the viscosity model

Solids concentration in the slurry (wt. \%)

Maximum solids concentration in the slurry (wt. \%)

Parameter in the viscosity model

Calibration factor of pressure transducer

Pressure drop along the pipeline $(\mathrm{cP})$

Length of the test section of the pipeline [m]

Temperature $\left[{ }^{\circ} \mathrm{C}\right]$

Apparent viscosity of the slurry [cP]

Maximum solids concentration of the slurry

Zero slurry flow rate in pipeline 
This report summarizes the research carried out at the Hemispheric Center for Environmental Technology (HCET) at Florida International University for Fiscal Year (FY) 1996 under the project "Rheological Properties of Defense Waste Slurries." The objective of this project is to address the needs of the nuclear waste vitrification process. The focus of the research has been on experimental study and model development for control of the vitrification melter feed rheology. The refined and reliable experimental data on the rheological properties of melter feed obtained from this work can be used to enhance the current design base for melter feed mixing and transportation systems, to improve the process' performance, and to reduce vitrification costs.

Experimental data collection and analysis of the rheological behavior of simulated melter feeds has been emphasized. Due to the unique properties of nuclear waste, much effort has been made to validate the experimental facility and correlate the observed data. In contrast to earlier rheological studies of melter feeds which covered relatively narrow parameter ranges, this study covers a wider range of solids concentration, $\mathrm{pH}$ value, and flow rate. The simulated waste slurry, which was composed of water, soluble metal salts, and insoluble solid particles, was obtained from DOE sites. This particular mixture has been used in order to simulate the actual product of a Defense waste treatment process. The apparent viscosity of the waste slurry has been measured under various feed and operating conditions in two measurement systems.

The experimental results indicate that the viscosity of the slurry is sensitive to both the concentration of solids and the $\mathrm{pH}$ of the solution. The measured viscosity has been correlated as a function of the solids contents based on fundamental fluid rheology theory. Special parameters were included in the model to describe various feed condition effects on the rheological behavior.

The effects of other important parameters on the viscosity of the selected waste slurries have been identified. These parameters are temperature and slurry chemical nature. For both the Savannah River (SRS) and Hanford site slurries, operaling temperature has been found to have only a slight effect on viscosity. Experimental observations of the $\mathrm{pH}$ values indicate that there is a viscosity peak around the $\mathrm{pH}$ value of 8 for the Hanford slurry, while the viscosity of SRS slurry increases as the $\mathrm{pH}$ increases from 4 to 13.5. At higher slurry temperatures, increased slurry viscosity in certain solids concentration range was observed, but the effect is less significant than that of concentration and $\mathrm{pH}$.

Application of these experimental and modeling results to the DWPF melter feeds preparation process can lead to the modification and enhancement of the technical base for the design of slurry transportation equipment and pipeline systems. The results also serve as important references for improving waste slurry mixing performance. All of these factors will contribute to an increase in the capabilities of the vitrification process and the quality of the waste glass. 


\section{INTRODUCTION}

Over the past 45 years, the United States has generated over $1.7 \times 10^{8}$ gallons of high-level waste (HLW), most of which as a result of the military program for Defense weapons production. For example, at the Savannah River site (SRS), spent fuel from the Department of Defense reactors was proposed to reclaim plutonium and uranium. The remaining radioactive materials, fission products, fuel components, and nonradioactive chemicals used in processing make up the HLW stored in underground tanks. The most hazardous of these wastes, HLW is a pressing environmental concern that is considered a high priority for treatment and permanent disposal.

The Defense Waste Processing Facility (DWPF) at the Savannah River site (SRS) is currently implementing advanced environmental technologies to treat high-level nuclear waste. Among those technologies, the vitrification process is an effective method that is utilized by the U.S. Department of Energy (DOE) to treat the thousands of tons of HLW distributed throughout the DOE Complex. Waste vitrification is a thermal process operated at high temperatures $\left(1100^{\circ}\right.$ to $1350^{\circ} \mathrm{C}$ ) to melt the HLW waste with silicon or other glass-based additives to produce a durable waste glass form. In this way, the hazardous and radioactive elements in the HLW are immobilized by incorporating them into borosilicate glass. The glass form will be permanently disposed of in a geologic repository. The vitrification technology has been developed and validated for full-scale operation at SRS and other DOE sites.

Vitrification melter feeds are composed of waste slurry, supernate, and glass-based additives. Many requirements must be satisfied before the melter feed is considered suitable for use in nuclear waste vitrification. Because of the multicomponent and multiphase nature of the waste stream, the performance of the vitrification equipment and the durability of the glass product depend significantly on the properties of the melter feed. These important properties include composition, mixing uniformity, and rheological behavior.

The rheological properties of the melter feed not only affect the performance of the resulting glass product and the process' operability but also serve as a technical base for process designs and modifications. For example, the viscosity of the slurry must be identified to design the slurry mixing system and calculate the power consumption for the agitation motor. To handle and transport the mixed feed to the vitrification melter, the slurry pump and pipeline system must be designed based on detailed information on the rheological properties of waste slurry. Moreover, the economy and cost of the process can be optimized if a reasonable balance is established between the cost of the transportation of the slurry, which is directly related to the rheological properties, and the consumption of power, which is used to evaporate the water in the slurry stream during the vitrification process in the melter.

The major objective of this two-year project is to obtain refined and reliable experimental data about the rheological properties of melter feeds. The research involves both experimental studies and model development. Two experimental facilities have been set up to measure viscosity and pressure drop. A mathematical model has been developed as a result of experimental observation and fundamental rheology theory. The model has the capability to predict the viscosity of melter slurries in the range of the experimental conditions. The final results of the investigation could be used to enhance the current design base for slurry transportation systems and improve the 
performance of the slurry mixing process. If successful, the cost of this waste treatment will be reduced and disposal safety will be increased.

The specific objectives for this project inciude:

1. Design, implementation, and validation of the experimental facility in both bench and pilot scales;

2. Identification and preparation of melter feed samples of both the Savannah River and Hanford waste slurries at multiple solids concentration levels;

3. Measurement and analysis of the melter feeds to determine the effects of the solids concentration, $\mathrm{pH}$ value, and other factors on the rheological properties of the slurries;

4. Correlation of the rheological properties as a function of the measured physical and chemical parameters; and

5. Transmission of the experimental data and resulting correlation to the DWPF to guide melter feed preparation and transport equipment design.

\subsection{FACTORS AFFECTING THE VISCOSITY OF SLURRIES}

Many operating parameters and feed variables can affect the rheological properties of waste slurries. These include temperature, concentration of the solute, the molecular weight of solute, pressure, suspended matter, and $\mathrm{pH}$ value. Following is a brief description of these factors and their influence on the rheology of the slurries.

\subsubsection{Temperature}

An inverse relationship exists between viscosity and temperature for most fluids. Typical data are shown in Figure 1, which plots the viscosity of solutions with different concentrations as a function of temperature. It can be noted in the bottom curve in this figure that the viscosity of S200 at $20^{\circ} \mathrm{C}$ is 580 centipoises (cP), and it falls steadily to $14 \mathrm{cP}$ at $100^{\circ} \mathrm{C}$. However, it is possibie that for some special non-Newtonian fluids this inverse relationship is not applicable. In this investigation, the relationship between the viscosity of Defense waste slurries and temperature has been found to be a complicated mechanism. 


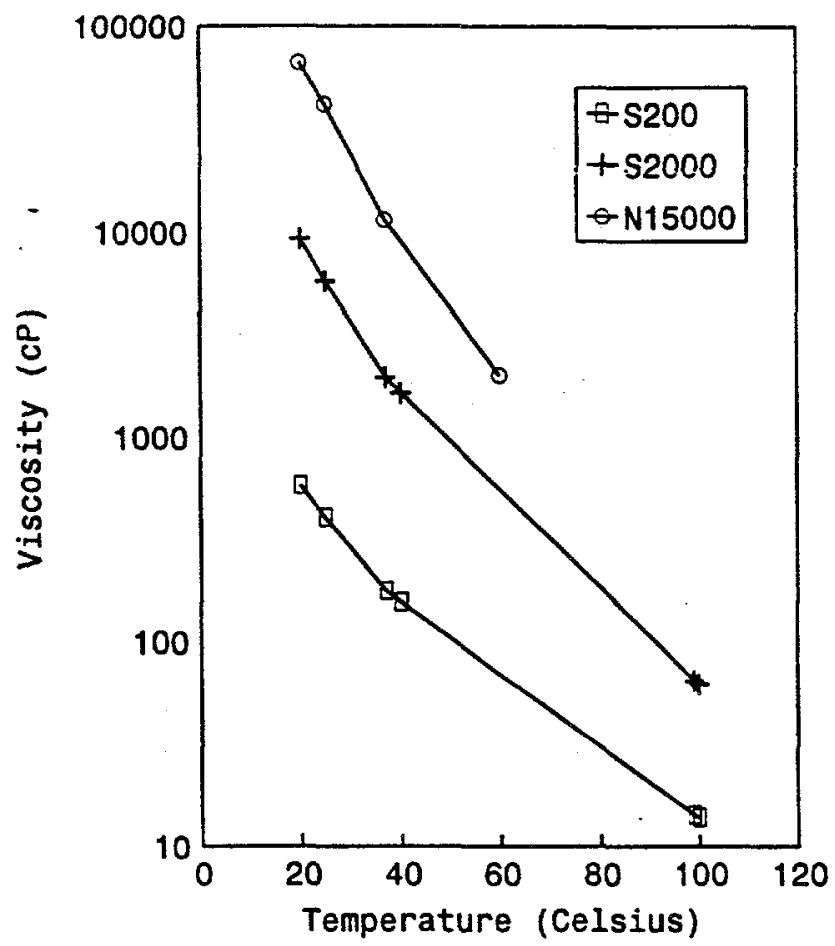

Figure 1. Viscosity as a function of temperature and concentration (high viscosity standards).

\subsubsection{Concentration of the Solute}

The dependence of the viscosity on the concentration of the solute is usually a direct nonlinear relationship: Figure 2 illustrates the viscosity-concentration behavior of water and sucrose solutions at three concentration levels. It can be observed at $20^{\circ} \mathrm{C}$ water has a viscosity of $1 \mathrm{cP}$, while the 60 percent sucrose solution has a viscosity of $80 \mathrm{cP}$ at the same temperature. For the slurries tested in this investigation, the effect of the concentration of the solute on the viscosity is indicated by the concentration of the supernate. 


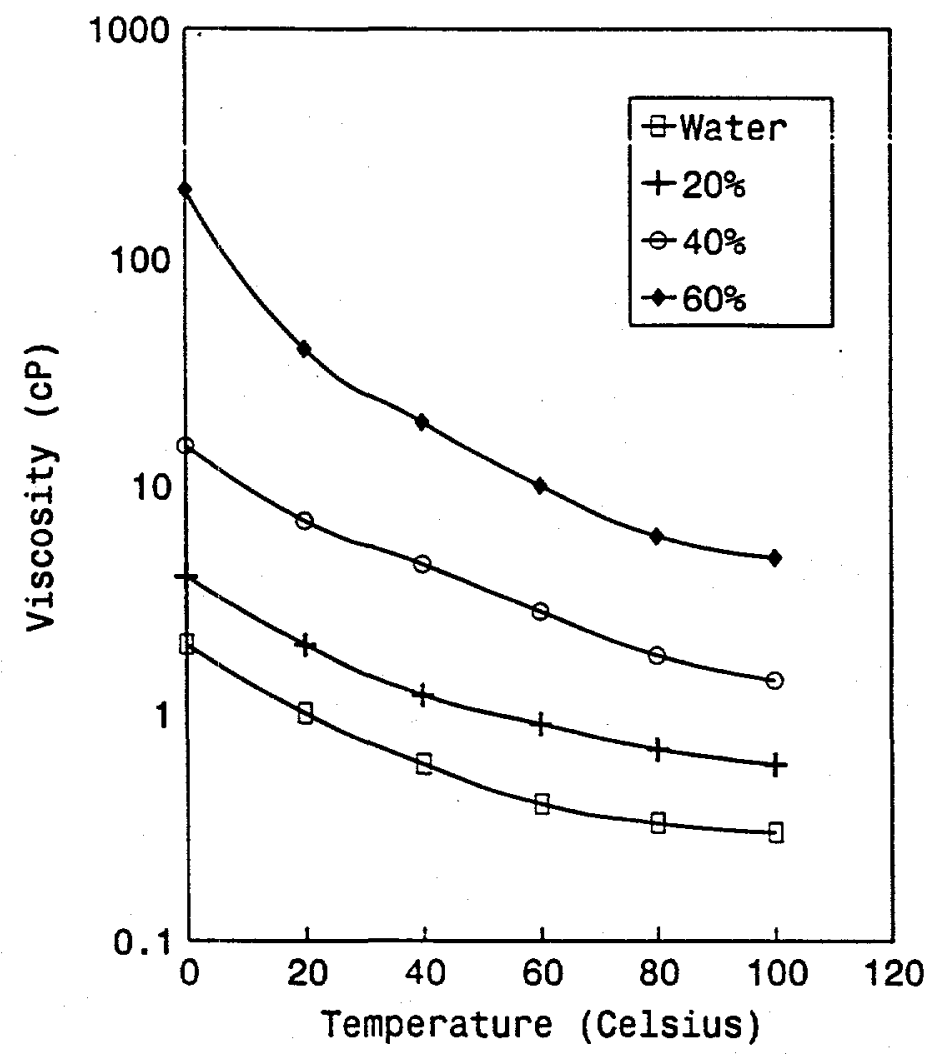

Figure 2. Viscosity as a function of solute concentration.

\subsubsection{Molecular Weight of the Solute}

A direct nonlinear relationship exists between the molecular weight of the solute and the viscosity of the solution at a constant concentration level. For most organic solutions, a solute with a high molecular weight will significantly increase the viscusity of the soiution. The viscosity of inorganic salt solution is slightly dependent on the molecular weight of the salt because these salts are of almost the same molecular size. Since the organic composition of waste slurries is very small, the molecular weight is not examined in this investigation.

\subsubsection{Pressure}

The viscosity of most liquids is essentially constant over a pressure range of 0 to 100 atmospheres. Hence, the effect of pressure on viscosity can usually be ignored for most organic and inorganic solutions.

\subsubsection{Suspended Matter}

The presence of suspended materials in a solution usually increases the viscosity slightly when these are in very low concentrations, but high concentrations of suspended matter can cause a 
substantial increase in viscosity beccause of the entanglement of the suspended particles. Concentrations of suspended matter usually render a solution that is in slurry state with nonNewtonian behavior. In extreme cases, high concentrations of suspended matter can lead to plastic or dilatant flows. In this investigation, it has been found that the concentration of suspended matter has important effects on the viscosity of waste slurries.

The size of the suspended solid particles and the size distribution can affect the viscosity of the slurry. The effects of size are indicated by a change in the contact surface of the solid-liquid interface, which plays an important role in the rheology of suspensions. This parameter will be investigated in future work.

This experimental investigation focuses on four parameters that represent the special characteristics of DWPF melter feeds. These parameters include: 1) slurry type, which reflects the chemical nature of the slurry; 2) solids concentration of both insoluble and soluble components; 3) $\mathrm{pH}$ value; and 4) temperature. These parameters are those used at the SRS vitrification facility to control the rheology of DWPF melter feeds. Our investigation concerns the rheological properties of specific slurry types under certain parameter ranges.

\subsection{REVIEW OF PREVIOUS INVESTIGATIONS}

The rheological properties of a vitrification feed simulating that used by the DWPF have been measured by the Savannah River Technology Center (SRTC) using a concentric cylindrical rheometer (Marek 1995). The consistency of the slurry was measured and correlated as a function of solids concentration. The simulated feed samples used in the experiment contained from 25 to 27 weight percent (wt. \%) insoluble solids. The temperature of the slurry was controlled at between $25^{\circ}$ and $50^{\circ} \mathrm{C}$, and no temperature effects were reported. The $\mathrm{pH}$ of the slurry was kept at constant, and the viscosity was measured under shear rates of 10 to $200 \mathrm{l} / \mathrm{s}$. The experimental observations were correlated by a Bingham plastic model with estimated parameters in the equation. Although the results reported were obtained using limited operating parameters, they serve as a helpful reference and guide for the present investigation.

A review of the research on multiphase pressure drop reveals that many studies have been conducted regarding two-phase (gas/liquid and solid/liquid) flow systems. For instance, the rheology of a coal slurry was studied by Round and Hessari (1987), who examined the effects of slurry $\mathrm{pH}$ and solid particle size distribution on the shear stress of water- and oil-based slurry using a Haake RV12 viscometer. Sellgren (1987) studied the effect of temperature on pressure drop and determined viscosity using a tube viscometer (diameter $=0.5 \mathrm{~cm}$ ). Temperaturedependent changes in rheological properties were evaluated for clay, coal, and iron ore slurries in the low temperature range of 0.50 to $20^{\circ} \mathrm{C}$. Much higher shear stress was observed when the temperature of the slurry approximated $0.5^{\circ} \mathrm{C}$.

Bouzaiene and Hassani (1992) reviewed and classified the pressure drop prediction methods reported in the literature. Several methods were examined using the available literature data on multiphase flow. For other types of multiphase phase flow systems, Lahey et al. (1992) tested global volumetric phase fraction in horizontal multiphase flows of gas, water, and oil. A detailed set of phasic volume fraction data was measured in a test loop 183 centimeters in length for the various flow regimes. The resulting data were then correlated with a generalized mathematical 
expressions. Unfortunately, no pressure drop measurements or correlations were reported by the researchers.

Kasiuri and Siepanek (1972a; i $972 \mathrm{~b}$ ) made a comprenensive study of the multiphase flow of air/corn/sugar/water and air/glycerol/water solutions in helical coil. Their investigation was limited to the influence of liquid properties and flow rates on void fraction and pressure drop. They treated the multiphase phase flow as a two-phase system composed of gas and a uniform solution. The experimental results were correlated using the Lockhart-Martinelli method.

As pressure drop and correlations for three-phase flow of nuclear wastes have not been widely investigated, the present study aims to shed light on the complicated three-phase flow system and provide basic rheological data for the design of pump and pipeline systems to be used in nuclear waste treatment processes. 


\section{EXPERIMENTAL SETUP AND SAMPLE PREPARATION}

The experimental design for measuring the rheological properties of DWPF melter feeds presents two options. The first.option consists of a batch system using a concentric cylinder viscometer. This experimental setup is used to measure the viscosity of slurries using a small amount of slurry in a glass beaker. The second option is a pipeline flow system that allows the slurry to flow continuously inside the pipeline. The viscosity of the slurry is obtained from the measurements of the pressure drop along the test tube.

\subsection{CONCENTRIC CYLINDER VISCOMETER}

The concentric cylinder viscometer rotates a sensing element in the slurry and measures the torque necessary to overcome the viscous resistance to the induced movement. This is accomplished by driving the immersed element, which is referred to as a spindle, through a beryllium copper spring via a pivot point assembly. This viscometer is able to measure a wide range of viscosities since viscosity is proportional to the torque windup of the spring connected to the spindle. The spindles of the rheometer and spindles' speed can be specified according to the solution's viscosity. The percentage of torque applied to the spindle due to the viscosity is related to the fluid's rheological behavior and the constant speed of the spindle.

Because of the unique characteristics of the DWPF melter feeds, this apparatus can only measure the viscosity of slurries at a low shear rate due to the effects of the particles' inertial force on the shear stress when the shear rate is high. The viscometer selected for this investigation is a Rheology International Shannon Ltd. rheometer model RI-1-L, considering its wider operating flexibility. It measures viscosities from 3 to $20,000 \mathrm{cP}$ by using different spindle types and adjusting the spindle speed. The measuring accuracy of this rheometer is $+/-1.0$ percent. The calibration data which is supplied by the manufacturer is shown in Table 1 .

Table 1.

Calibration Data from (Calibration standard: $103 \mathrm{cP} @ 25^{\circ} \mathrm{C}$ )

\begin{tabular}{|c|c|c|}
\hline Speed (RPM) & Torque (\%) & Viscosity (cP) \\
\hline 10 & 16.21 & 98 \\
20 & 33.59 & 101 \\
30 & 50.84 & 102 \\
50 & 85.58 & 102.7 \\
\hline
\end{tabular}

Source: Rheology International Shannon, Ltd.

Two other viscosity standards have been used to calibrate the viscometer at various operating conditions. The first viscosity standard is the calibration solution provided by Cambridge 
Applied Systems, Inc. These solutions are Q3E, Q6E, Q20E, and K60, which are of viscosity range from 3 to $100 \mathrm{cP}$ at a temperature of $25^{\circ} \mathrm{C}$.

A calibraiion curve measured using these standard solutions is shown in Figure 3.

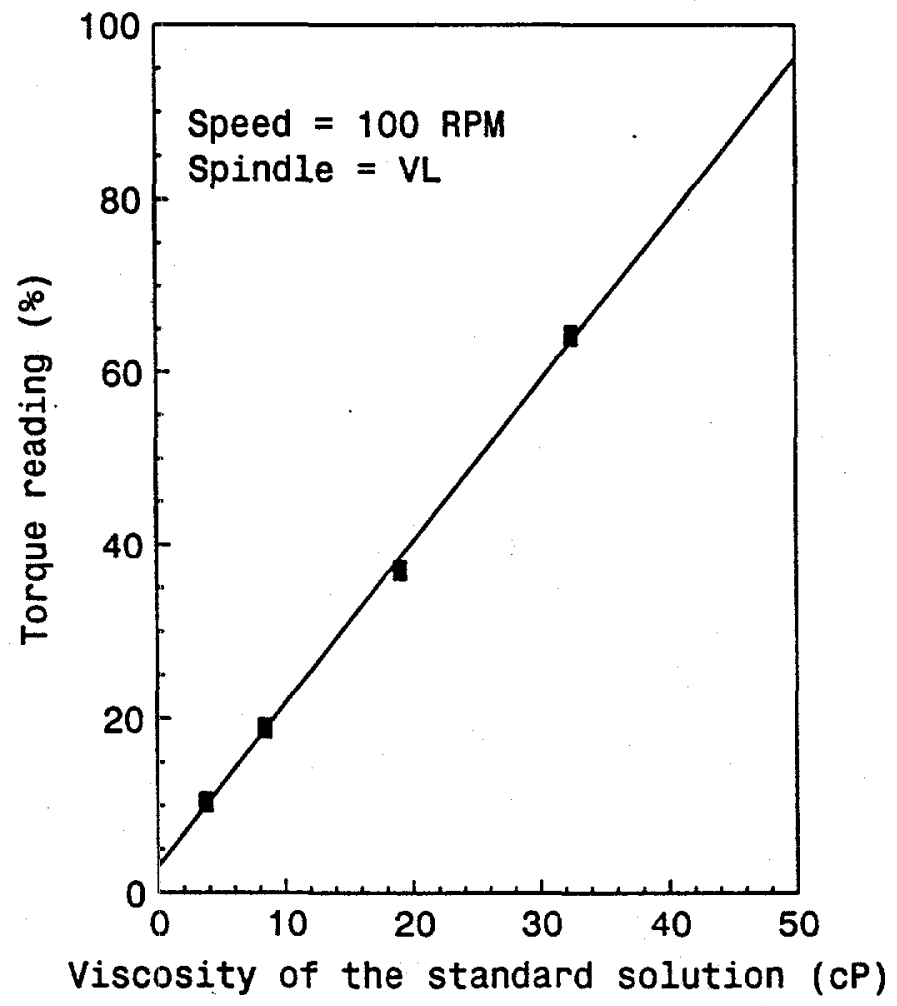

Figure 3. Rotational viscometer calibration curve using the low viscosity standard.

When the solids concentration in the slurry is higher than $10 \mathrm{wt}$. \%, viscosity of over $100 \mathrm{cP}$ is observed in the measurement. To cover the high-concentration measurements in the experiments, the viscometer has also been calibrated using high viscosity standards. These standards were provided by Fisher Scientific. The viscosity ranges indicated by Fisher Scientific are listed in Table 2. The temperature dependence for the viscosity of these standards has been presented in Figure 1. 
Table 2.

Viscosity Range of the High Viscosity Standard

\begin{tabular}{|c|c|c|}
\hline S200 & S2000 & N1500 \\
\hline 14 to $580 \mathrm{cP}$ & 62 to $9332 \mathrm{cP}$ & $2695 \mathrm{cP}$ to $66999 \mathrm{cP}$ \\
\hline
\end{tabular}

Source: Fisher Scientific.

The viscometer was calibrated using these standards. The calibration data using the high viscosity standards are presented in Tables 3 and 4 . These calibrations have been performed at constant temperature of $23^{\circ} \mathrm{C}$ using different spindle types.

Table 3.

Calibration Data Using High Viscosity Standards: S200

\begin{tabular}{|c|c|c|}
\hline $\begin{array}{c}\text { Spindle Speed } \\
\text { (RPM) }\end{array}$ & $\begin{array}{c}\text { Torque Reading } \\
\text { (Spindle-2) }\end{array}$ & $\begin{array}{c}\text { Torque Reading } \\
\text { (Spindle-3) }\end{array}$ \\
\hline 6 & 8.65 & \\
\hline 10 & 14.4 & 5.31 \\
\hline 12 & 17.5 & 6.0 \\
\hline 20 & 29.5 & 9.53 \\
\hline 30 & 43.6 & 14.3 \\
\hline 50 & 75.5 & 24.5 \\
\hline 60 & 90.6 & 29.5 \\
\hline 100 & over & 49.43 \\
\hline 60 & 90.6 & 29.5 \\
\hline 100 & over & 49.43 \\
\hline
\end{tabular}


Table 4.

Calibration Data Using High Viscosity Standards: S2000

\begin{tabular}{|c|c|c|}
\hline $\begin{array}{c}\text { Spindle Speed } \\
\text { (RPM) }\end{array}$ & $\begin{array}{c}\text { Torque Reading } \\
\text { (Spindle-3) }\end{array}$ & $\begin{array}{c}\text { Torque Reading } \\
\text { (Spindle-4) }\end{array}$ \\
\hline 2.5 & 14.6 & \\
\hline 3 & 17.3 & 5.7 \\
\hline 5 & 28.7 & 7.0 \\
\hline 6 & 34.6 & 11.7 \\
\hline 10 & 57.3 & 14.1 \\
\hline 12 & 69.9 & 23.5 \\
\hline 20 & over & 35.2 \\
\hline 30 & over & 59.2 \\
\hline 50 & over & 71.5 \\
\hline 60 & over & over \\
\hline 100 & over & \\
\hline
\end{tabular}

The concentric spindle rheometer offers the advantage of providing quick and direct output of rheological information at a lower shear rate range using a small amount of sample. The disadvantage is that it is difficult to control uniform concentration in the test vessel when the solids concentration is high. Another concern is that at a high shear rate the particle deposition on the outer cylinder surface may affect the accuracy of the measuring results. (Marek 1995)

\subsection{PIPELINE FLOW SYSTEM}

To ensure that the slurry was well mixed and to minimize the effect of particle precipitation on the measurement, a pipeline flow system was designed to conduct the experiment at a pilot scale. The rheological properties of the DWPF slurry were obtained from pressure drop measurements along the test tube. A schematic representation of this experimental setup is shown in Figure 4. 


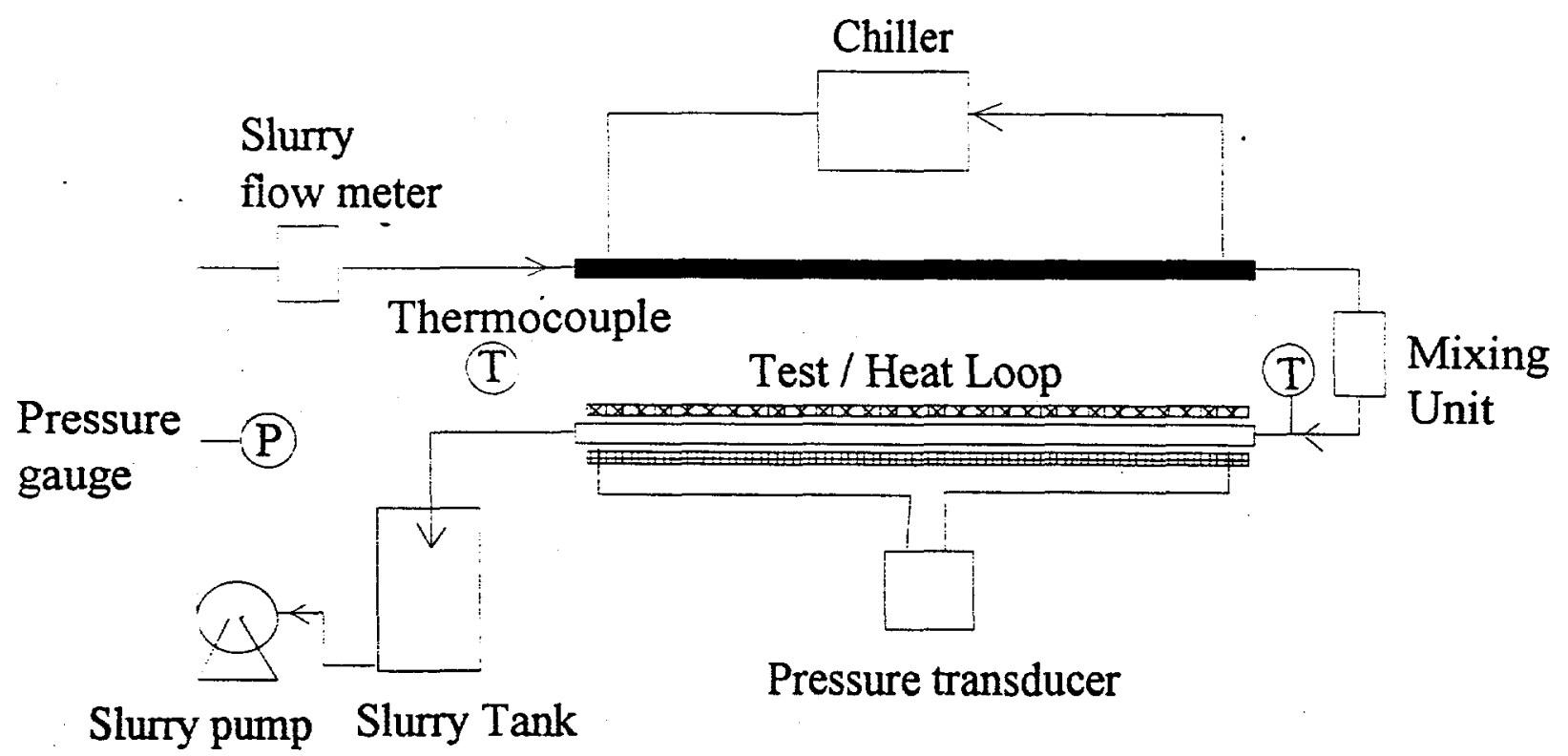

Figure 4. Schematic of the experimental pipeline flow system.

The DWPF waste slurry was well mixed and prepared at a constant concentration and $\mathrm{pH}$ value before it was loaded into the slurry tank. During operation, the slurry was pumped out from the mixture reservoir into the pipeline system. It passed through a flow meter and a cooling section into the slurry mixing unit. The two-phase mixture then flowed through a visual section located approximately 30.5 centimeters downstream from the mixing unit, entered the test loop, and finally returned to the slurry tank. A pressure gauge was mounted on the outlet of slurry pump to measure the discharge pressure, and a thermocouple was inserted into the slurry tank to measure the temperature of the slurry. A five meter-long introduction section was placed between the pump and the test loop to eliminate entrance effects and enhance the mixing.

The test loop consisted of a horizontal stainless-steel pipe 2.14 meters in length with an inner diameter of 0.025 meter. The stainless-steel pipe was electrically heated to maintain the inside mixture at the specified temperature. Coolant produced from the chiller flowed through the jacket of the cooling section to adjust the temperature of the slurry inside the test tube. Pressure drop along the test section was measured using a differential pressure transducer (wet-wet), which was routinely calibrated before performing each set of experiments. The reading on the indicator was related to the pressure drop according to the following equation:

$$
\Delta \mathrm{P}=\left(\mathrm{Am}-\mathrm{A}_{0}\right) \cdot \mathrm{F}
$$

where $\Delta \mathrm{P}$ denotes the pressure drop (psi), Am represents readings at different slurry flow rates, $\mathrm{A}_{0}$ is a baseline reading obtained when the fluid velocity in the tube is zero, and $\mathrm{F}$ is a calibration factor. This kind of pressure drop measurement system has successfully been used to measure the rheological properties of a gibbsite slurry produced by the nitrate to ammonia and ceramic (NAC) process (Ebadian 1996). 


\subsection{WASTE SLURRY SAMPLE PREPARATION}

The simulated melter feed slurries were supplied by the Savannah River Technology Center (SRTC). The tôtal volume ôt each type of simulani was approximateiy 15 liters. The simulants were composed of supernate and concentrated slurry. They were delivered in separate bottles.

\subsubsection{Sample Analysis}

The sample analysis was conducted by the technical staff at the Savannah River Technology Center for both simulant types. A typical composition of the Savannah River Site slurry is shown in Table 5, while a typical composition of the Hanford slurry is shown in Table 6. In Table 5, the total solids shown include insoluble, soluble, and calcined solids. The metal compositions in the slurry were analyzed using atomic absorption (AA). Other organic/inorganic components were determined by instrumental and wet-chemistry analytical methods. The original $\mathrm{pH}$ of the slurries was determined to be approximately 13 for the Savannah River Site slurry and 10 for the Hanford slurry. The soluble salt concentration in the supernate and the insoluble solids concentration in the concentrated slurry were identified using the drying method. The samples were dried in a oven with a controlled temperature of $70^{\circ} \mathrm{C}$.

Table 5.

Analytical Results of the SRS Sludge (ID\# 32897)

\begin{tabular}{|l|c|c|}
\hline Components & $\begin{array}{c}\text { Concentration (wt. \%) } \\
\text { (Dry basis) }\end{array}$ & $\begin{array}{c}\text { Analytical Error } \\
\text { (+/-wt. \%) }\end{array}$ \\
\hline $\mathrm{Al}$ & 6.67 & 0.4 \\
\hline $\mathrm{Ca}$ & 2.67 & 0.15 \\
\hline $\mathrm{Cr}$ & 0.18 & 0.02 \\
\hline $\mathrm{Fe}$ & 26.8 & 1.55 \\
\hline $\mathrm{Mg}$ & 1.31 & 0.08 \\
\hline $\mathrm{K}$ & 0.14 & 0.003 \\
\hline $\mathrm{Mn}$ & 2.8 & 0.16 \\
\hline $\mathrm{Na}$ & 10.2 & 0.6 \\
\hline $\mathrm{Ni}$ & 0.24 & 0.02 \\
\hline $\mathrm{Pb}$ & 0.1 & 0.01 \\
\hline $\mathrm{Si}$ & 0.81 & 0.05 \\
\hline $\mathrm{Zn}$ & 0.17 & 0.01 \\
\hline $\mathrm{SO}_{4}$ & 0.33 & 0.02 \\
\hline $\mathrm{PO}_{4}$ & 0.84 & 0.03 \\
\hline
\end{tabular}


Table 5.

Analytical Results of the SRS Sludge (ID\# 32897)(Continued)

\begin{tabular}{|l|c|c|}
\hline \multicolumn{1}{|c|}{ Components } & $\begin{array}{c}\text { Concentration (wt. \%) } \\
\text { (Dry basis) }\end{array}$ & $\begin{array}{c}\text { Analytical Error } \\
\text { (+/- wt. \%) }\end{array}$ \\
\hline $\mathrm{C}_{2} \mathrm{O}_{4}$ & 0.2 & 0.01 \\
\hline $\mathrm{CO}_{3}$ & 1.94 & 0.1 \\
\hline $\mathrm{NO}_{3}$ & 1.96 & 0.05 \\
\hline $\mathrm{NO}_{2}$ & 5.86 & 0.03 \\
\hline $\mathrm{OH}$ & 2.95 & 0.05 \\
\hline Total organic carbon & $<50$ ppm* & \\
\hline Total solids & 26.29 & 0.5 \\
\hline
\end{tabular}

* Parts per million

Table 6.

Analytical Results of the Handford Sludge (ID\# 200053234)

\begin{tabular}{|l|c|c|}
\hline \multicolumn{1}{|c|}{ Components } & Concentration & Unit \\
\hline $\mathrm{Al}$ & 6.30 & wt. $\%$ \\
\hline $\mathrm{Ca}$ & 0.448 & wt. $\%$ \\
\hline $\mathrm{Cr}$ & 0.006 & 0.02 \\
\hline $\mathrm{Fe}$ & 27.3 & 1.55 \\
\hline $\mathrm{Mg}$ & 0.193 & 0.08 \\
\hline $\mathrm{K}$ & 0.003 & 0.003 \\
\hline $\mathrm{Mn}$ & 2.22 & 0.16 \\
\hline $\mathrm{Na}$ & 1.38 & 0.6 \\
\hline $\mathrm{Ni}$ & 2.44 & 0.02 \\
\hline $\mathrm{Pb}$ & $<0.004$ & 0.01 \\
\hline $\mathrm{Si}$ & 0.238 & 0.05 \\
\hline Zn & 0.017 & 0.01 \\
\hline Ammonium & $<100$ & $\mathrm{MG} / \mathrm{L}$ \\
\hline Fluoride & 0.84 & $\mathrm{MG} / \mathrm{L}$ \\
\hline Formate & 0.2 & $\mathrm{MG} / \mathrm{L}$ \\
\hline Chloride & 1.94 & $\mathrm{MG} / \mathrm{L}$ \\
\hline Nitrite & 1.96 & $\mathrm{MG} / \mathrm{L}$ \\
\hline Nitrate & $2.148 \mathrm{E} 3$ & $\mathrm{MG} / \mathrm{L}$ \\
\hline
\end{tabular}


Table 6.

Analytical Results of the Hanford Sludge (ID\# 200053234) (Continued)

\begin{tabular}{|l|c|c|}
\hline \multicolumn{1}{|c|}{ Components } & Concentration & Unit \\
\hline Sulfate & 359 & $\mathrm{MG} / \mathrm{L}$ \\
\hline Total organic carbon & 510 & $\mathrm{ppm}$ \\
\hline Total inorganic carbon & 189 & $\mathrm{ppm}$ \\
\hline
\end{tabular}

* Milligrams per liter

** Parts per million

\subsubsection{Sample Preparation}

A series of samples were prepared at different total solids concentration levels by mixing the supernate and the concentrated slurry. Figure 5 shows the relationship between the solids concentration and the ratio of the suspension to the total volume. This diagram can help to estimate the solids concentration based on the volumetric suspension ratio in a well-precipitated slurry.

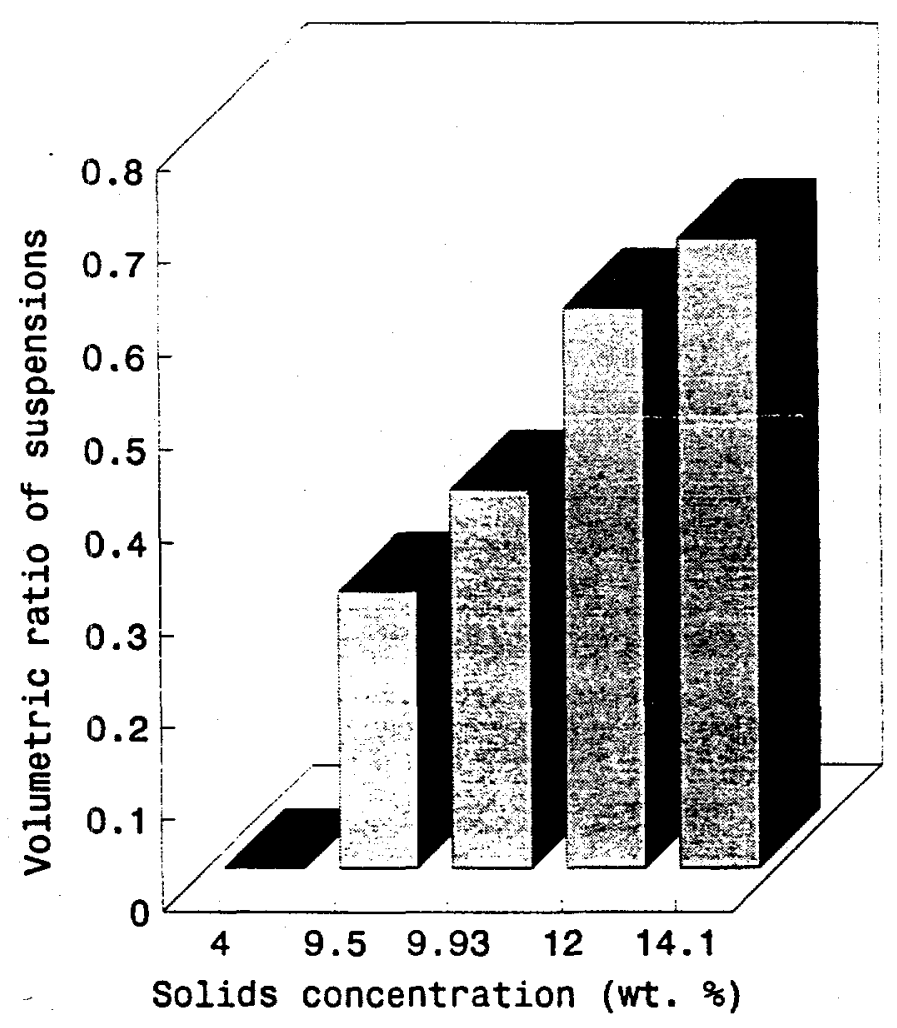

Figure 5. Relationship between the solids concentration and the suspension ratio. 
Table 7 shows the concentrations of samples of the Savannah River Site and Hanford slurries. Before using the samples in the rotational viscometer measurement, each sample was mixed thoroughly to obtain a homogeneous mixture. The $\mathrm{pH}$ values of the sample at selected solids concentration were adjusted by the addition of sulfuric acid $\left(\mathrm{H}_{2} \mathrm{SO}_{3}\right)$. To adjust the slurry $\mathrm{pH}$ back to its original value and to check the measurement's consistency in the two $\mathrm{pH}$ changing directions, sodium hydroxide $(\mathrm{NaOH})$ was also used to increase the slurry $\mathrm{pH}$ value. For each well-mixed sample, the $\mathrm{pH}$ value was measured using $\mathrm{AgCl} /$ reference electrodes and a digital $\mathrm{pH}$ meter.

Table 7.

Prepared Sample Concentration

\begin{tabular}{|c|c|c|}
\hline Sample & $\begin{array}{c}\text { Concentration } \\
\text { (wt. \%) SRS Slurry }\end{array}$ & $\begin{array}{c}\text { Concentration } \\
\text { (wt. \%) Hanford Slurry }\end{array}$ \\
\hline 1 & 5.5 & 5.7 \\
\hline 2 & 9.5 & 7.6 \\
\hline 3 & 12 & 9.3 \\
\hline 4 & 9.9 & 11.5 \\
\hline 5 & 14.1 & 15.0 \\
\hline
\end{tabular}




\section{EXPERIMENTAL STUDY USING A ROTATIONAL VISCOMETER}

For both the SRS and Hanford slurries, investigations have been conducted with five solids concentrations. Nine temperature points and ten $\mathrm{pH}$ levels have been examined under a specified solids concentration.

\subsection{MEASUREMENT METHOD}

The concentric rotational rheometer offers the advantage of providing quick and direct output of rheological information at a certain shear rate range. The disadvantage is that it is difficult to control uniform concentration and temperature in the test vessel when the solids concentration is high. To enhance the concentration's uniformity inside the test beaker, the slurry was well mixed before the spindle was inserted. The temperature gradient was minimized by heating the sample beaker in a water bath and measuring the slurry temperature at different points along the radius direction until the same temperature reading was obtained.

\subsection{PARAMETRIC INVESTIGATIONS}

The slurry types used for testing were the SRS and Hanford slurries. For each, the following parameters have been investigated: solids concentration, $\mathrm{pH}$, and temperature.

\subsubsection{Effect of the Concentration of Solids}

For each simulant, five samples were prepared at different total solids concentration levels by mixing the supernate and the concentrated slurry. The details of the solids concentration are shown in Table 7. Before measurement, each sample was loaded into a $400 \mathrm{ml}$ glass beaker and mixed thoroughly to obtain a homogeneous mixture. The viscometer was set up at the "autozero" option, and the spindle was run in air to obtain a reading of zero before the spindle was inserted into the sample beaker. The measured viscosity of the slurries and its dependency on the solids concentration are shown in Figures 6 through 9. The results obtained regarding the SRS slurry are presented in Figures 6 and 7. Those for the Hanford slurry are presented in Figures 8 and 9. 


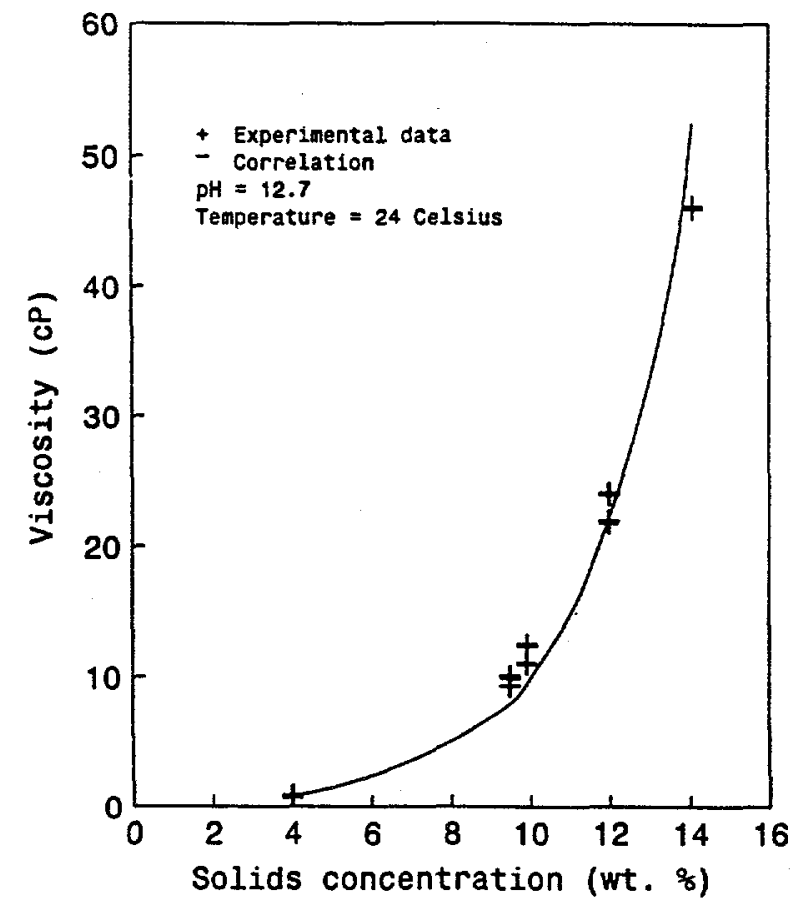

Figure 6. Viscosity (in linear scale) as a function of solids concentration.

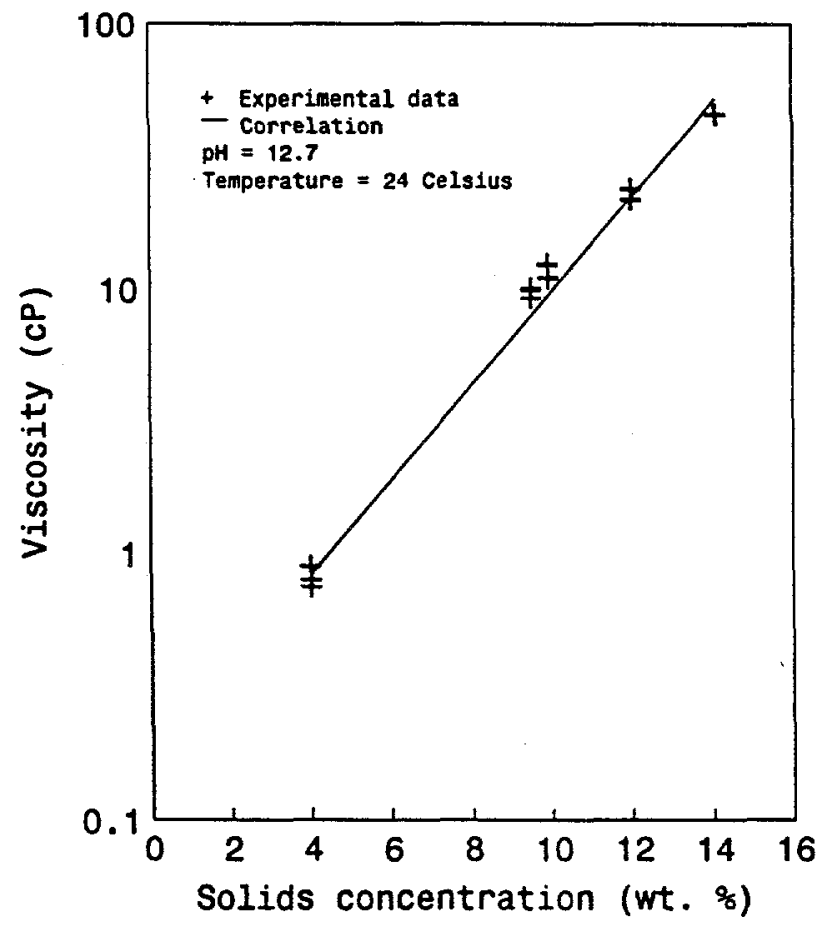

Figure 7. Viscosity (in long scale) as a function of solids concentration (SRS slurry). 


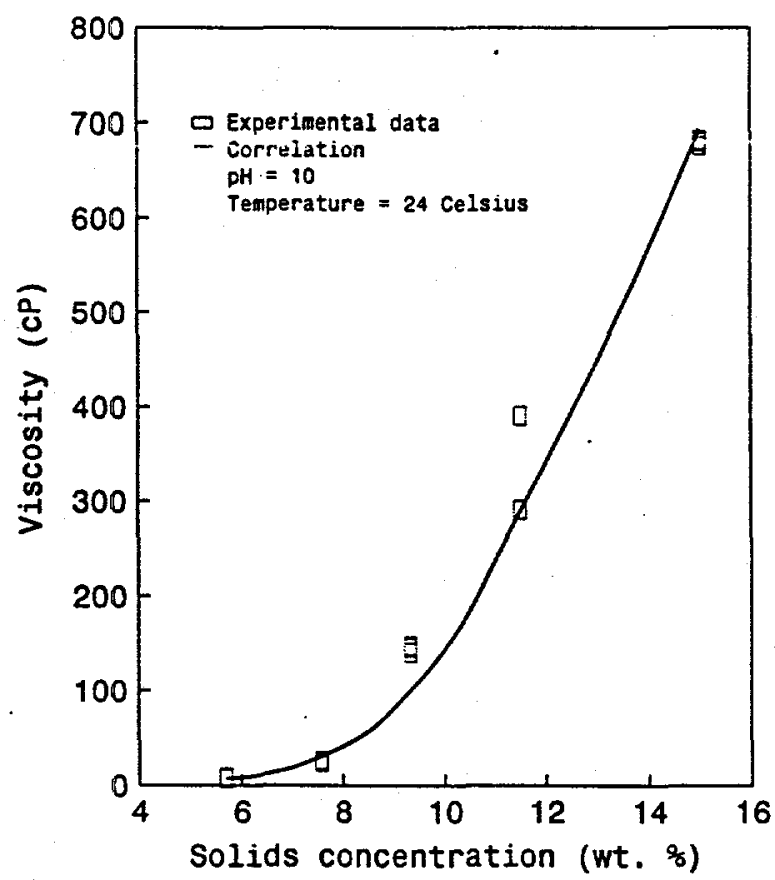

Figure 8. Viscosity (in linear scale) as a function of solids concentration (Hanford slurry).

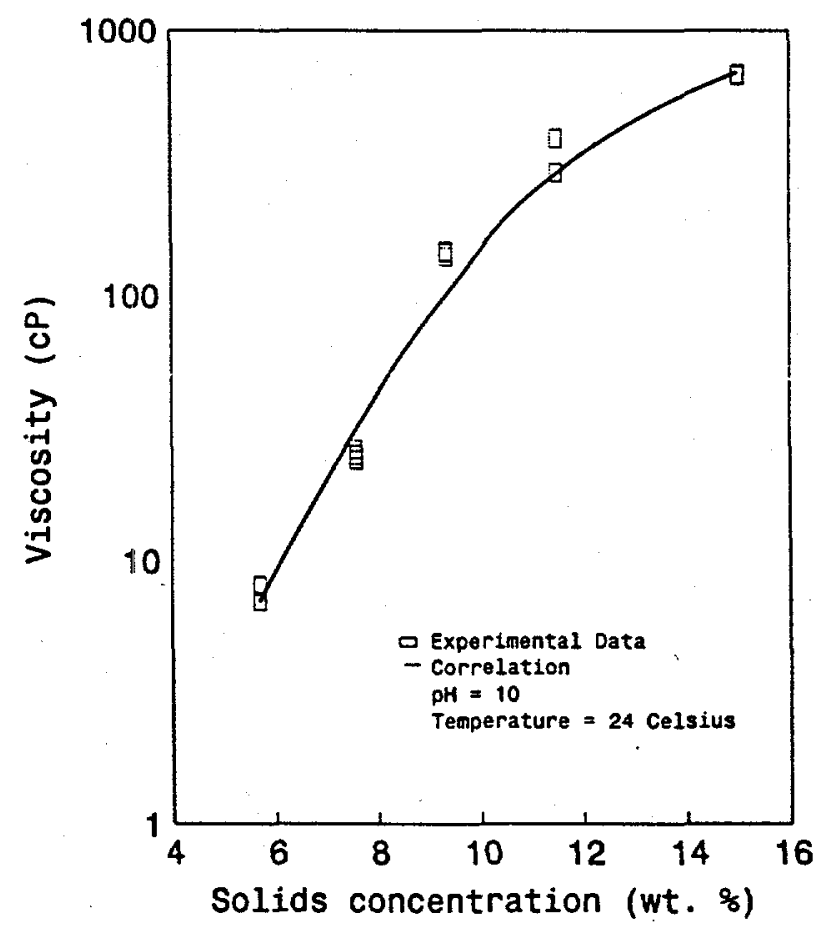

Figure 9. Viscosity (in long scale) as a function of solids concentration (Hanford slurry). 


\subsubsection{Effects of the pH on the Slurries Tested}

The $\mathrm{pH}$ values of the slurry at selected solids concentrations were adjusted by the addition of sulfuric acid $\left(\mathrm{H}_{2} \mathrm{SO}_{3}\right)$. To adjust the slurry $\mathrm{pH}$ back to its original value, sodium hydroxide $(\mathrm{NaOH})$ was used. The $\mathrm{pH}$ value of the slurry was measured using $\mathrm{AgCl} /$ reference electrodes and a digital $\mathrm{pH}$ meter. For both the slurries under specified concentration, the $\mathrm{pH}$ was adjusted at several levels from a minimum of 4 to a maximum of 13.5. During the addition of sulfuric acid $\left(\mathrm{H}_{2} \mathrm{SO}_{3}\right)$, chemical reaction heat was released, and the temperature of the slurry increased. To keep the temperature at constant, the reaction heat was removed by placing the sample tank in a cold-water bath. When the temperature reached the specified. value, the measurement was initiated. The volumetric effect due to the addition of liquid acid and a solid base will be discussed in the results discussion section. Table 8 lists these $\mathrm{pH}$ value changes following the addition of sulfuric acid $\left(\mathrm{H}_{2} \mathrm{SO}_{3}\right)$ and sodium hydroxide $(\mathrm{NaOH})$. The arrows in the table indicate the $\mathrm{pH}$ 's changing direction. The effects of $\mathrm{pH}$ on the viscosity of both the SRS and Hanford slurries are shown in Figures 10 and 11.

Table 8.

$\mathrm{PH}$ Value Adjusted with $\mathrm{H}_{2} \mathrm{SO}_{4}$ and $\mathrm{NaOH}$

\begin{tabular}{|l|l|l|l|l|l|l|l|l|l|l|}
\hline $\mathrm{H}_{2} \mathrm{SO}_{4}$ Addition \\
\hline $\mathrm{pH}$ & 12.94 & 8.62 & 8.56 & 8.45 & 6.45 & 6.08 & 5.65 & 5.29 & 4.58 & 4.27 \\
\hline $\mathrm{NaOH}$ Addition \\
\hline $\mathrm{pH}$ & 12.95 & 11.77 & 9.85 & 9.61 & 9.0 & 8.45 & 7.08 & 5.99 & 5.03 & 4.27 \\
\hline
\end{tabular}




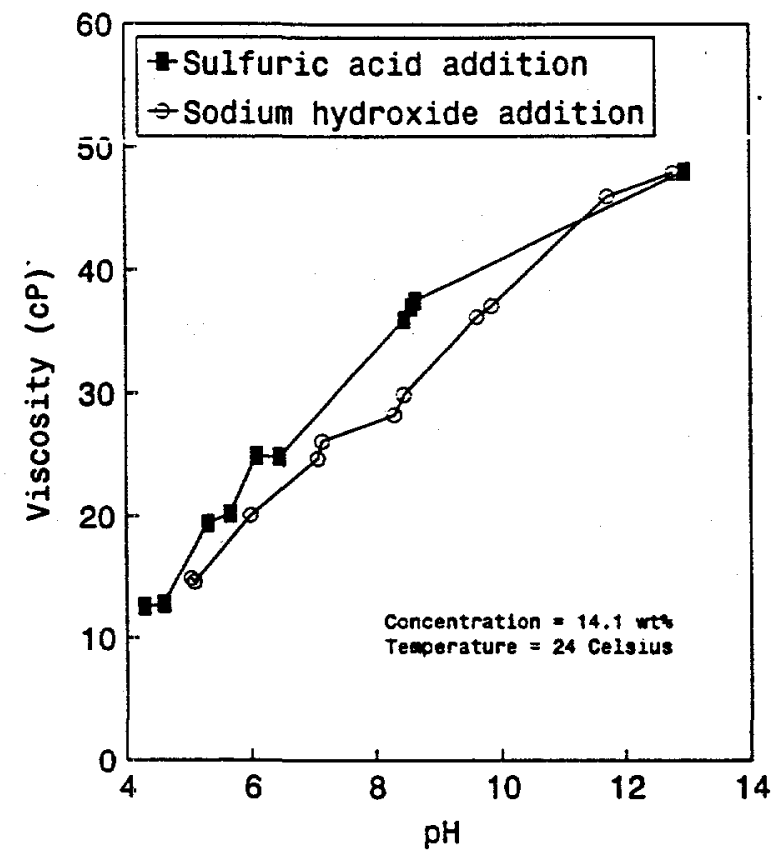

Figure 10. Viscosity as a function of pH (SRS slurry).

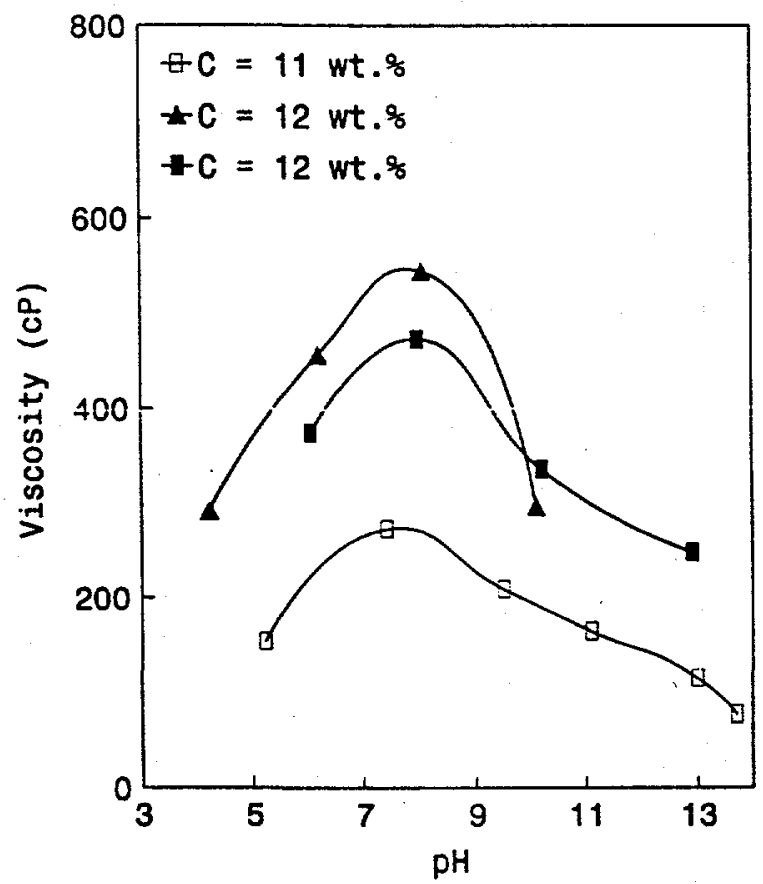

Figure 11. Viscosity as a function of $\mathrm{pH}$ (Hanford slurry. The pH was adjusted using sulfuric acid for the upper and bottom curves and sodium hydroxide for the middle curve). 


\subsubsection{Effects of Temperature}

The temperature effect on the viscosity of the slurry has been investigated from room temperature to the maximum slurry operating temperature, $66^{\circ} \mathrm{C}$. The temperature was maintained under $66^{\circ} \mathrm{C}$ to avoid chemical reactions in the slurry at high temperatures and water evaporation from the slurry. In both of these cases, the composition and concentration of the slurry would be influenced. The temperature of the slurry was raised from $25^{\circ} \mathrm{C}$ to $66^{\circ} \mathrm{C}$ using a Fisher Scientific water bath. At each temperature level, enough heating time was needed to ensure a thermal equilibrium was reached in the slurry.

The effect of temperature has been examined for both the SRS and the Hanford slurries. Two concentration levels were used for to test for temperature effects on the SRS slurry. Experimental observations are presented in Figures 12 and 13.

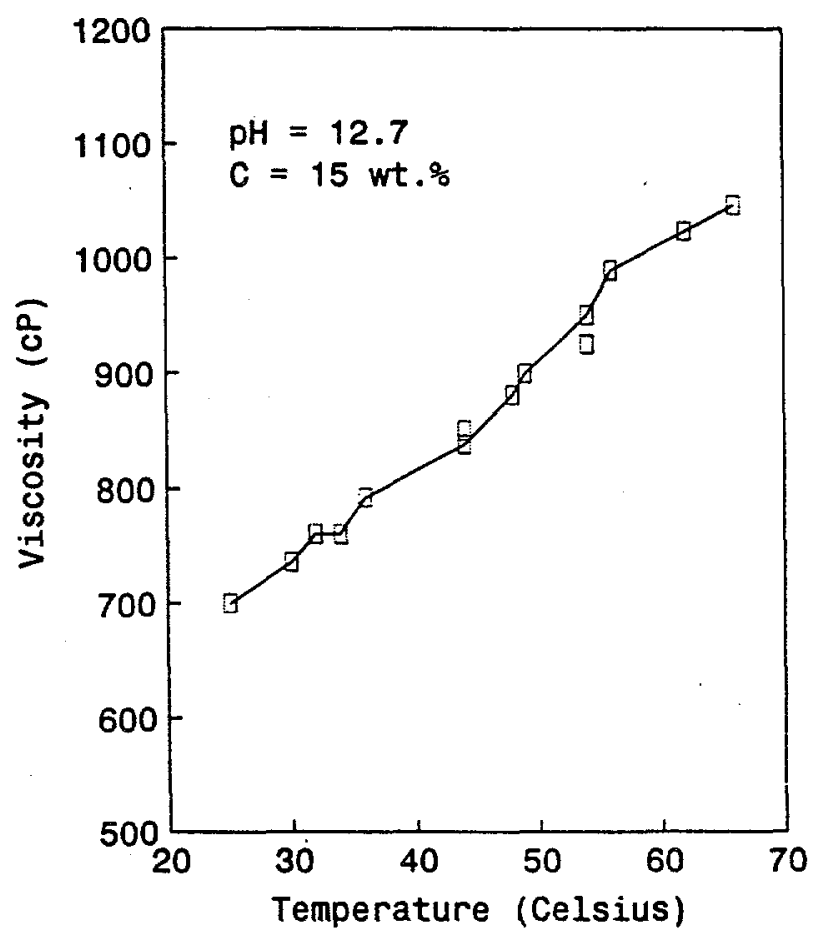

Figure 12. Viscosity as a function of temperature (SRS slurry). 


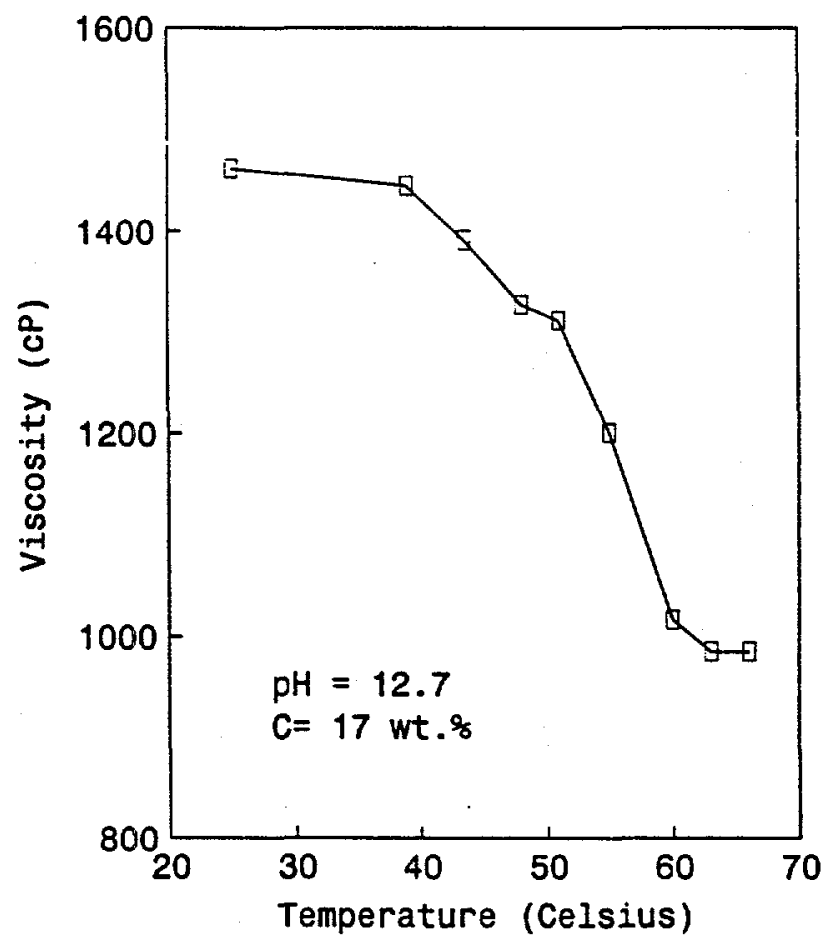

Figure 13. Viscosity as a function of temperature (SRS slurry).

One concentration level was investigated for the Hanford slurry. The results of the testing are shown in Figure 14. All temperature effect experiments were conducted under constant $\mathrm{pH}$ and viscometer operating conditions. Unlike other regular fluids which have consistent temperature dependencies, the DWPF melter feed simulants showed quite different temperature-viscosity relationships at different concentrations level. For example, at a concentration of $15 \mathrm{wt}$. \%, the viscosity of the SRS slurry increased as the temperature increased, but it decreased as the temperature increased when the concentration was as higher as $17 \mathrm{wt} . \%$. On the other hand, for the Hanford slurry at a concentration of $12 \mathrm{wt} . \%$, the viscosity increased when the temperature increased. 


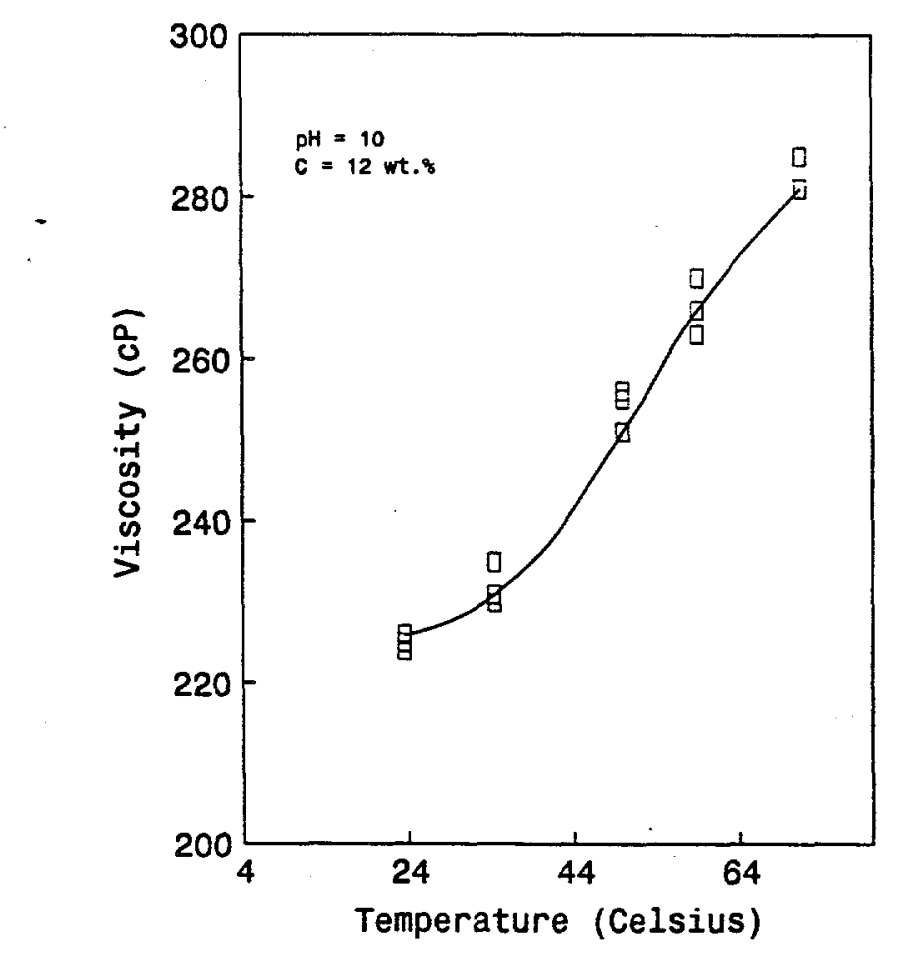

Figure 14. Viscosity as a function of temperature (Hanford slurry).

\subsection{RESULTS AND DISCUSSIONS}

For both the Savannah River and Hanford slurries, the experimental observations indicate that viscosity is strongly dependent on the solids concentration, especially in the high solids concentration range. For example, for the SRS slurry, at $10 \mathrm{wt}$ \% solids concentration, the viscosity of the slurry is approximately $10 \mathrm{cP}$, whereas the viscosity is high as $50 \mathrm{cP}$ at $14 \mathrm{wt}$. \% solids concentration (see Figure 7). A much higher viscosity, $1450 \mathrm{cP}$, was observed when the solids concentration increased to $17 \mathrm{wt} \%$, as can be seen in Figure 13 .

Experimental observation indicates that the relationship between the viscosity of the slurry and the concentration of the slurry is an exponential function. This is shown in Figures 6 and 8. For the SRS slurry, the exponential index is a constant because Figure 8 shows a linear relationship between the viscosity and the concentration. On the other hand, the exponential index for the Hanford slurry seems to be a function of other related factors. This is indicated by the non-linear relationship shown in Figure 9. The details of the mathematical equations with respect to these relationship are presented in Section 5.

The second factor that affects the slurry viscosity is its $\mathrm{pH}$ value. Figure 10 shows the $\mathrm{pH}$ effect on the SRS slurry. The data were obtained at different $\mathrm{pH}$ adjusted by both sulfuric acid and sodium hydroxide. In both $\mathrm{pH}$-changing cases, the data indicate that the viscosity of the slurry increases with the $\mathrm{pH}$ value. Lower viscosity has been observed during the sodium hydroxide addition. Moreover, there are some dilution effects on the concentration of the slurry during the 
sulfuric acid addition. The effect is not important, however, because the amount of the added sulfuric acid is much smaller compared to sample volume.

The resuits obtained from the sodium hydroxide addition indicate that the eirects of the $\mathrm{pH}$ on the viscosity of the slurries are due to chemical actions rather than physical dilution because the $\mathrm{NaOH}$ addition did not cause any concentration drop in the slurry. It should be noted that the $\mathrm{pH}$ effect on viscosity has different mechanisms for different slurry types. We have observed that there is a direct proportional relationship between viscosity and $\mathrm{pH}$ for the SRS slurry (see Figure 10), but there are viscosity peaks in the Hanford slurry in the $\mathrm{pH}$ range of 7 to 8 (see Figure 11).

Compared to the effects of solids concentration and the $\mathrm{pH}$ value, the temperature of the slurry seems to have has less effect on the viscosity of the slurry. However, the changes in viscosity due to temperature increases are still considerable in terms of the actual operating conditions. In Figures 12 and 14, it can be seen that there is an increase of about 30 percent in the viscosity when the temperature is raised from $25^{\circ} \mathrm{C}$ to $66^{\circ} \mathrm{C}$. It has been observed that at high solids concentration, the effect of temperature on the viscosity is opposite to that which occurs at low concentrations. These phenomena need to be verified in future work by testing other slurry samples at different concentrations. 


\section{EXPERIMENTAL STUDY USING THE PIPELINE FLOW SYSTEM}

To run the experiments at a high shear rate as required by the next step of this study, a pipeline viscometer was utilized. This setup consisted of a continuous flow system for measuring pressure drop along the test tube. Rheological properties were obtained from the pressure drop data. The test loop consisted of a horizontal stainless-steel pipe 0.025 of a meter in inner diameter and 2.14 meters in length. A four-meter-long tube (with the same diameter as the test loop) was installed between the slurry pump and the test tube to enhance the mixing of the slurry and eliminate the entrance effect. The stainless-steel pipe was electrically heated to maintain the inside mixture at the specified temperature. The outside of the test loop was insulated with thermal insulation materials.

The procedure used to run the pipeline system was as follows:

1. Mix the slurry at the specified concentration, and load the slurry into the slurry pump reservoir;

2. Open the valve at the reservoir exit;

3. Turn on the slurry pump at the specified $\mathrm{Hz}$ number on the pump's remote controller;

4. Adjust the pump speed according to the required slurry flow rate;

5. Turn on the heating equipment to heat up the slurry to the specified temperature;

6. Adjust the coolant flow rate to control the temperature of the slurry at constant;

7. Activate the data acquisition system;

8. Activate the pressure transducer and Am indicator;

9. Observe the slurry flow rate, pressure drop, temperature, and the pressure at the pump exit; and

10. Take data until the above observations reach their stable values;

\subsection{PRESSURE DROP MEASUREMENT}

The pressure drop along the test tube was measured using a pressure transducer. The transducer used two plastic tubes (two meters long and one-quarter inch in diameter) as pressure sensors connected to the ends of the test section. The plastic tube and the transducer were filled with water (assuming that water is an incompressible fluid). The transducer was routinely calibrated with water.

The transducer converted the pressure drop measured from the test tube into an electrical signal (Am) and displayed the signal on an indicator. The pressure transducer was calibrated by taking readings at various heights in the water column. The relationship between the Am reading and the inch-water is a linear function, which is described in Equation (1). 


\subsection{PARAMETRIC INVESTIGATIONS}

The SRS slurry was measured in the pipeline system under various experimental conditions. For these experiments, four parameters were investigared to examine their effects on the pressure drop of the slurry. These parameters included slurry flow rate, solids concentration, temperature, and $\mathrm{pH}$ value. The parameter ranges covered by the experiments are shown in Table 9.

Table 9.

Experimental Cases in the Pipeline Flow System

\begin{tabular}{|l|l|l|l|l|l|l|l|}
\hline Experiment \# & 1 & 2 & 3 & 4 & 5 & 6 & 7 \\
\hline Concentration (wt. \%) & 0 & 10 & 25 & & & & \\
\hline $\mathrm{pH}$ & 13.5 & 11.2 & 8 & & & & \\
\hline Temperature ( $\left.{ }^{\circ} \mathrm{C}\right)$ & 25 & 35 & 55 & & & & \\
\hline Flow rate $\left(\mathrm{LPM}^{*}\right)$ & 5 & 10 & 15 & 20 & 25 & 30 & 35 \\
\hline
\end{tabular}

* Liters per minute

The effect of the solids concentration on the pressure drop is shown in Figure 15, in which water (solids concentration $=0$ ) is used as a baseline to compare it with the slurry. From this figure, we can see that with the increase of solid concentration in the slurry, the fluid flow inside the tube becomes more and more difficult due to the increase in slurry viscosity and shear stress, which results in the higher pressure gradient along the pipeline. 


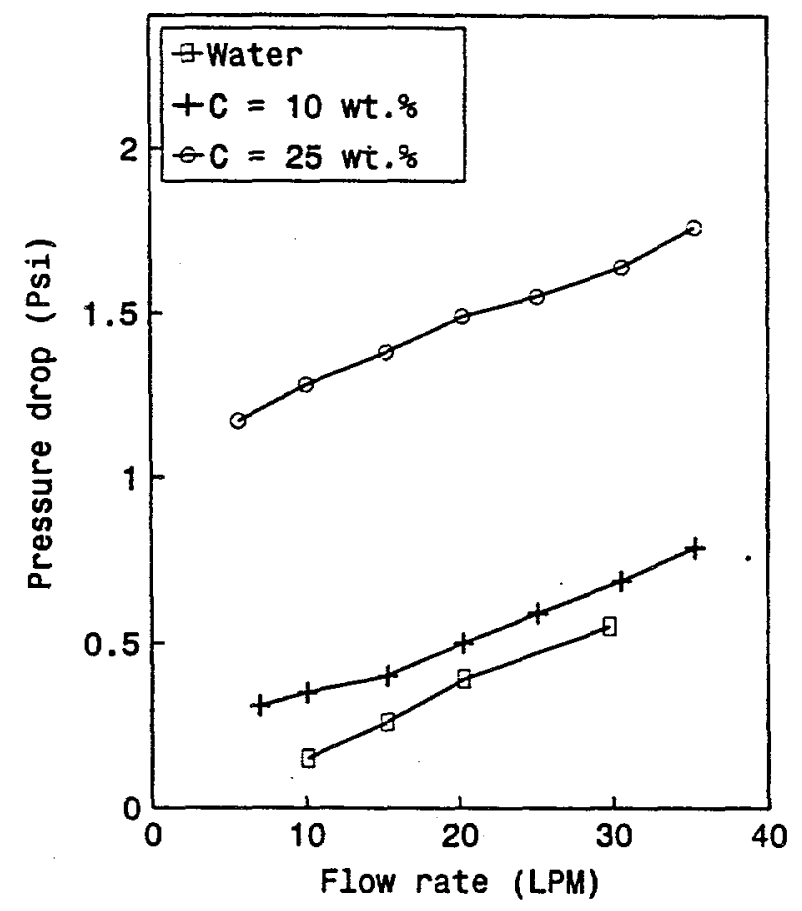

Figure 15. Pressure drop as a function of solids concentration (SRS slurry).

The $\mathrm{pH}$ effect on the slurry is presented in Figure 16, which shows data measured at three $\mathrm{pH}$ levels and a constant solids concentration of $25 \mathrm{wt}$. \%. These measurements were conducted under the constant temperature of $25 \mathrm{C}^{\circ}$.

The results obtained from the pipeline system are consistent with those measured using the rotational viscometer, that is, the viscosity of the SRS slurry increases when its $\mathrm{pH}$ increases. For example, at a medium-high slurry flow rate of 20 liters per minute, the pressure drop increases about 50 percent at $\mathrm{pH}=13.5$ compared to that at $\mathrm{pH}=8$. We did not test the slurry under a $\mathrm{pH}$ value lower than 8 because of the possibility of corrosion of the pump due to the acidic slurry.

The effect of temperature on the pressure drop of the slurry was examined at three levels $-25^{\circ} \mathrm{C}$, $35^{\circ}$, and $55^{\circ} \mathrm{C}$ - under a constant slurry concentration of $25 \mathrm{wt} . \%$. These measurements were conducted under a constant $\mathrm{pH}$ of 13.5. The experimental observations are shown in Figure 17. At the particular solids concentration and $\mathrm{pH}$, a higher pressure drop was observed at higher temperatures. In this figure, it can be noted that the pressure drop was 1.7 psi at room temperature and $2.8 \mathrm{psi}$ at $55^{\circ} \mathrm{C}$ under the same slurry flow rate.

All the investigations of solids concentration, $\mathrm{pH}$, and temperature were accomplished by varying the slurry flow rate. In both of the cases run, the relationship between the slurry velocity and pressure drop is indicated by an approximate linear function in a certain parameter range. The trend exhibited by the pressure drop according to the slurry flow rate can be observed in Figures 15,16 , and 17. 


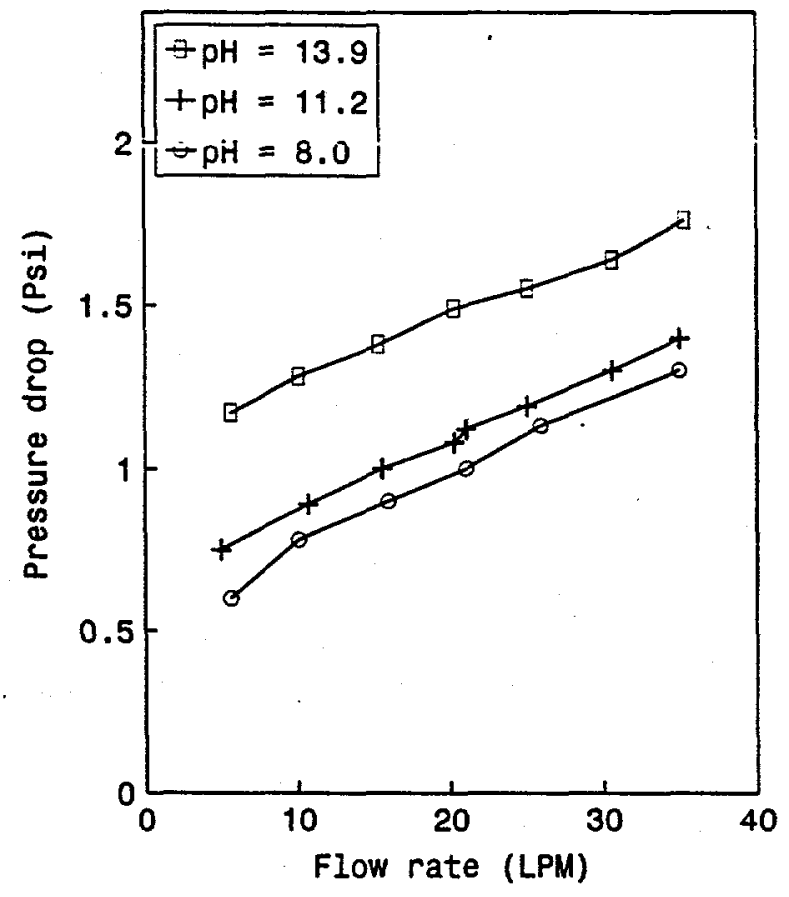

Figure 16. Pressure drop as a function of $\mathrm{pH}$ (SRS slurry).

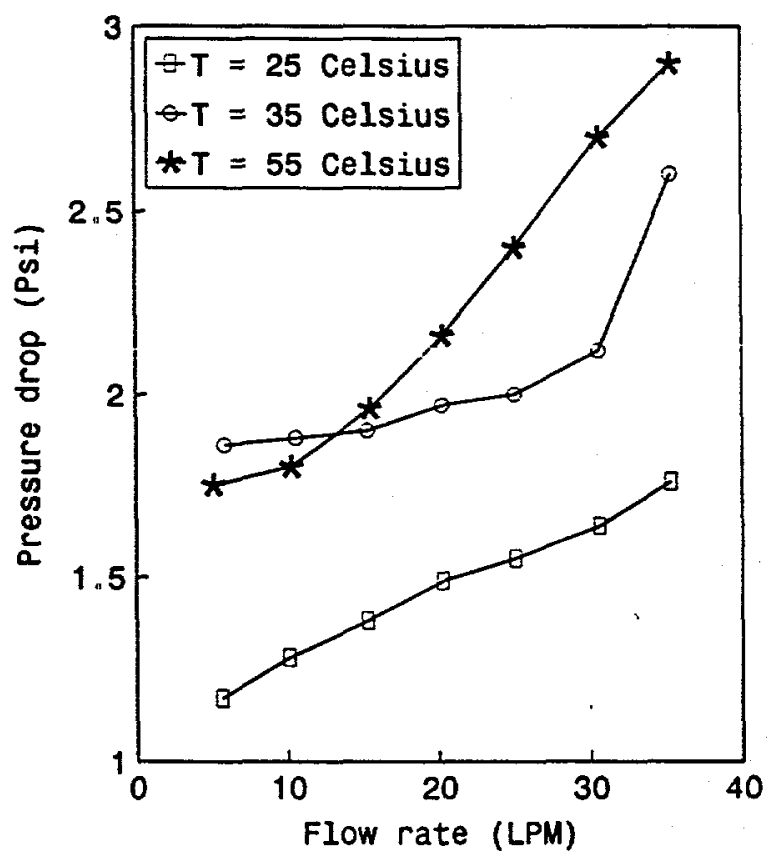

Figure 17. Pressure drop as a function of temperature (SRS slurry). 


\subsection{RESULTS AND DISCUSSION}

For the effect of temperature on the viscosity, there is usually an inverse relationship, that is, the fluid's viscosity decreases as the temperature increases. Typical data are shown in Figure 1, which plots the viscesity of solutions as a function of temperature. We have observed this relationship in our experiments for a $17 \mathrm{wt}$ \% SRS slurry (see Figure 13). On the other hand, we also observed that this relationship is not applicable for the SRS slurry at low solids concentrations ( $12.7 \mathrm{wt}$. \%) measured using the rotational viscometer and higher solids concentration ( $\sim 25 \mathrm{wt} . \%)$ measured using the pipeline measurement system.

The effect of $\mathrm{pH}$ on the viscosity of the slurry has been observed in both measurement systems. The assumed mechanism for the $\mathrm{pH}$ effect is that a stern layer and a diffusion electrical double layer are formed around the solid particles at a low $\mathrm{pH}$ value. Thus, the strong aggregation of particles is prevented by the electric force, and the shear stress between the particles is reduced. The strength of this repulsive force is an indication of the $\mathrm{pH}$ value. At high $\mathrm{pH}$ values, on the other hand, the charges are reduced, which increases the possibility of the formation of larger particles and promotes resistance to moving these particles, which results in a high viscosity of the slurry. It is possible that there is a minimum electrical charges for compositions such as the Hanford slurry in a certain $\mathrm{pH}$ range. Therefore, a maximum viscosity would exist for this special condition. Further experiments and analysis are required to clarify this phenomenon. 


\section{DATA ANALYSIS AND CORRELATION}

The experimentai data and modei predictions for the effect of solid concentration on the viscosity of the SRS slurry are shown in Figures 6 and 7. The solids concentrations were studied at a constant temperature and.pH value. Experimental observations indicate that the concentration exerts a strong effect on the viscosity of the slurry. When the solids concentration increases to over $10 \mathrm{wt}$. $\%$, the viscosity rises dramatically to a high value. To make a correlation for the experimental data and predict the rheological properties of slurries at high solids concentrations, a mathematical model was selected to describe this rheological behavior. It follows:

$$
\mu=A e^{B C} \frac{1}{\left(1-\frac{C}{C_{\max }}\right)}
$$

where $\mu$ represents the apparent viscosity (cP) of the slurry, $\mathrm{C}$ denotes the solids concentration (wt. \%); and $\mathrm{C}_{\max }$ represents the maximum solids concentration the slurry can handle. Parameters $\mathrm{A}$ and $\mathrm{B}$ were determined by performing a Least-Squares fit to the experimental data using this equation. The correlation results under the specification of $C_{\max }=100$ were $A=0.16(\mathrm{cP})$ and $\mathrm{B}$ $=0.4$. A comparison of the measured viscosity and the model predictions for typical slurry $\mathrm{pH}$ and operation temperatures is also shown in Figures 6 and 7.

It is interesting to note that in the viscosity model if the solids concentration was zero, (i.e., the slurry turned into a liquid state with a certain $\mathrm{pH}$ value), the viscosity was equal to the value of parameter $\mathrm{A}$, which is only a function of $\mathrm{pH}$ and temperature. If the solids concentration increased to the its maximum value of $\mathrm{C}_{\max }$, (i.e., there is a solids concentration of 100 percent in the slurry), the viscosity obtained from the model went up to infinity, which indicates the viscosity of solid state materials.

The Hanford slurry shows different rheological behavior from the SRS slurry, which has been observed in the experimental investigations. Two features are exhibited by the Hanford slurry viscosity in its dependency on the solids concentration: 1) the slurry is of much higher viscosity than the SRS slurry at same solids concentration and 2) the solids concentration dependency indicates a more complex exponential function with the viscosity. We have checked the mathematical model [Equation (2)] with the experimental data measured from the Hanford slurry and found that this model needs to be modified to predict the data.

Based on the special theology behavior of the Hanford slurry, a mathematical model similar to Equation (2) but with an additional parameter has been developed to correlate the data. The model is described by the following equation:

$$
\mu=A e^{\left(B C+D C^{2}\right)} \frac{1}{\left(1-\frac{C}{C_{\max }}\right)}
$$


where $D$ is another parameter to be regressed from the data and $C_{\max }$ is still defined as a maximum solids concentration of $100 \mathrm{wt}$. \%. The parameters correlated to the data have following values:
$\mathrm{A}=0.011(\mathrm{cP})$
$\mathrm{B}=1.36$
$\mathrm{D}=-0.042$

Even though we consider this model to be an empirical correlation and no physical explanation exists for these parameters, the format of the model is consistent with that proposed by Marek (1994). The model can also be interpreted at the two extreme points, that is, the zero and 100 percent concentrations. The viscosity calculated from this model has been plotted in both Figures 8 and 9. The agreement between the experimental data and the model prediction is reasonable. We are developing a rheological model to correlate the data from the measurements obtained from the pipeline system. The model is not presented in this report as it requires validation with more data that will be collected during FY97 work. 


\section{MAJOR ACCOMPLISHMENTS AND CONCLUSIONS}

In the present investigation, viscosity measurements have been carried out for two types of simulated Defense waste slurries, a Savannah River slurry and a Hanford slurry. The measurements were conducted in two experimental options. A rotational viscometer was used to measure viscosity under well-defined temperature and $\mathrm{pH}$ value operating conditions. The solids concentration used for this option was lower than $15 \mathrm{wt}$. \%. Both the slurries have been investigated using this experimental option. The Savannah River slurry has also been investigated in a pipeline flow system, which measured the pressure drop as the slurry flowed through the pipe. The slurry's viscosity can be extracted from the pressure drop information.

These investigation have been performed in relatively wide parameter ranges. The solids concentration of the slurry tested in the pipeline system was as high as $25 \mathrm{wt} . \%$. The slurry $\mathrm{pH}$ in both experimental options covered a range of 4 to 13.5. The highest operating temperature was $66^{\circ} \mathrm{C}$ for the rotational viscometer and $55^{\circ} \mathrm{C}$ for the pipeline system. In FY97, the experiments for the Hanford slurry in the pipeline system will be performed.

Based on the identification of the slurry's rheological behavior, two mathematical models have been developed, to correlate the data obtained from the rotational viscometer measurements. The model correlated the experimental data very well in the specified parameter range. The experimental data and the modeling results both indicate that the amount of solids present in the slurry exerts the strongest effect on the viscosity, especially in the higher concentration range. For the Hanford slurry, the viscosity can exceed $1500 \mathrm{cP}$ when the solids concentration surpasses $17 \mathrm{wt} . \%$ at room temperature.

The effects of $\mathrm{pH}$ on viscosity were observed in both experimental options, and the results are consistent. We have found that there is a maximum viscosity around the $\mathrm{pH}$ range of 7 to 9 for the Hanford slurry. This information is important because it can be used in actual operations to reduce the viscosity of the slurry by adjusting the slurry $\mathrm{pH}$ lower than 7 or higher than 9 . Based on the data and the chemical characteristics of the slurry, an assumed mechanism is proposed to explain the $\mathrm{pH}$ effect phenomena. The initial resulis obtained from this study will be used as a reference for future work involving higher solids concentration and other types of slurries.

The operating temperature used in both experimental options was varied from room temperature to $55^{\circ}$ and $66^{\circ} \mathrm{C}$. Within this temperature range, the viscosity of the slurry exhibited an increasing trend at lower solids concentrations and a decreasing trend at higher solids concentration, as observed using the rotational viscometer. In the pipeline measurement system, it has been found that the pressure drop exhibited by the SRS slurry along the test tube increases as the operating temperature rises from $25^{\circ}$ to $55^{\circ} \mathrm{C}$ for a $25 \mathrm{wt}$. \% concentration slurry.

Application of these experimental and modeling results to the DWPF melter feed preparation process could modify and enhance the technical base for designing slurry transportation equipment and pipeline systems. They can also serve as an important reference for improving waste slurry mixing performance and reducing melter operating limitations. 


\section{RFCEIVFD}

NOY U? 1998 REFERENCES

$\mathcal{O} S \mathbf{I}$ hassani, F.P., 1992, "A Selection of Pressure Loss Predictions Based on Slurry/Backfill Characterization and Flow Conditions," CIM Bulletin 4, 63-68.

Ebadian, M.A., 1996, Final Report on the Nitrate to Ammonia and Ceramic/Glass Process, Hemispheric Center for Environmental Technology Center (HCET), Miami.

Marek, J.C., 1995, Rheological Properties of Simulated SRS Vitrification Feeds, Presented at the I\&EC Special Symposium, American Chemical Society, Atlanta, GA..

Marek, J.C., 1994, Baseline Task Technical Plan to Develop Technical Bases for Rheology Control of DWFP Melter Feed Preparation Process, WSRC-RP-94-558, Rev. 0, Westinghouse Research Center, Aiken, SC.

Kasturi, G. and Stepanek, J.B., 1972a, "Two-Phase Flow-I. Pressure Drop and Void Fraction Measurement in Concurrent Gas-Liquid Flow in a Coil," Chemical Engineering Science 27, 1871-1880.

Kasturi, G. and Stepanek, J.B., 1972b, "Two-Phase Flow-II. Pressure Drop and Void Fraction Measurement in Concurrent Gas-Liquid Flow in a Coil," Chemical Engineering Science $27,1881-1891$.

Lahey R.T., Jr., Acikgoz, M., and Franca, F.,, 1992, "Global Volumetric Phase Fraction in Horizontal Three-Phase Flow," AICHE Journal 38, 1049-1058.

Lockhart R.W. and Martinelli, R.C., 1949, "Proposed Correlation of Data for Isothermal TwoPhase, Two-Component Flow in Pipes," Chemical Engineering Progress 45, 39-47.

Round G.F. and Hessari, A.R., 1987, "Rheology of Coal Slurry: pH and Size Distribution Effects," in Particulate and Multiphase Processes, eds. T. Ariman, and T.N. Veziroglu, Hemisphere Publishing Corporation, New York, 329-340.

Sellgren A., 1987, "Some Temperature Effects on Slurry Rheology in Cold Regions," in Particulate and Multiphase Processes, eds. T. Ariman and T.N. Veziroglu, Hemisphere Publishing Corporation, New York, 235-243. 